\title{
LA PROPUESTA DE UN TRIBUNAL INTERNACIONAL CONTRA EL TERRORISMO: RETOS JURÍDICOS Y POLÍTICOS
}

ALEJANDRO SÁNCHEZ FRÍAS 
SUMARIO

1. INTRODUCCIÓN. 2. ¿QUÉ ACTOS JUZGAR? DEFINICIÓN Y NATURALEZA DEL CRIMEN DE TERRORISMO: 2.1 LA ETERNA BÚSQUEDA DE LA DEFINICIÓN DEL TERRORISMO. 2.2 CRIMEN INTERNACIONAL VS CRIMEN TRANSNACIONAL. 3. ¿CUÁL SERÍA SU RELACIÓN CON OTROS TRIBUNALES? PRIMACÍA VS COMPLEMENTARIEDAD. 4. ¿CUÁL SERÍA SU BASE JURÍDICA? LEGITIMIDAD Y CONSENSO VS RAPIDEZ Y EFICACIA. 5. ¿HACIA UNA SUPERACIÓN DE LOS OBSTÁCULOS JURÍDICOS A NIVEL POLÍTICO? 6. CONCLUSIONES. 


\title{
LA PROPUESTA DE UN TRIBUNAL INTERNACIONAL CONTRA EL TERRORISMO: RETOS JURÍDICOS Y POLÍTICOS
}

\author{
ALEJANDRO SÁNCHEZ FRÍAS ${ }^{1}$ \\ Investigador Predoctoral (FPU) en Derecho Internacional Público \\ y Relaciones Internacionales
}

\section{INTRODUCCIÓN}

La oleada de ataques terroristas sufridos en Europa, Oriente Medio, África y Asia fue uno de los principales puntos tratados por el Consejo de la Unión Europea durante la reunión celebrada el 9 de febrero de $2015^{2}$. Respondiendo a su llamada de adoptar las medidas que sean necesarias para asegurar imperio de la ley en la lucha contra esta amenaza, el ministro de asuntos exteriores de Rumanía invitó a reflexionar sobre la creación de una jurisdicción internacional competente en materia de terrorismo ${ }^{3}$. Poco después la idea fue respaldada por España y Países Bajos, animados por la Declaración de Madrid de julio de 2015 en la que se llamaba a los Estados a proponer «creative ideas and new approaches for developing legal tools to further coun-

${ }^{1}$ Investigador predoctoral (FPU). Área de Derecho Internacional Público y Relaciones Internacionales Facultad de Derecho. Universidad de Málaga Bulevar Louis Pasteur, 26, 29010 Málaga. Email: asanchezfrias@uma.es. Máster en Estudios de la Unión Europea (Universidad de Salamanca) y Máster en Derecho Europeo (Colegio de Europa, Brujas). El presente artículo se enmarca en el programa de ayudas de investigación FPU del Ministerio de Educación, Cultura y Deporte (FPU-2015/06775), así como en el proyecto del Ministerio de Economía y Competitividad «Los muros en el Derecho Internacional contemporáneo: consecuencias para la seguridad, la dignidad humana y la sostenibilidad» (DER-2015-65486-R) y el Grupo de Investigación «Protección Internacional de los Derechos Humanos, Seguridad y Medioambiente (SEJ-593)» del Plan Andaluz de Investigación.

${ }^{2}$ Council conclusions on counter-terrorism, de 9 de febrero de 2015. Disponible en:

http://www.consilium.europa.eu/en/press/press-releases/2015/02/150209-council-conclusions-counter-terrorism/ (Consultado el 21 de julio de 2017).

${ }^{3}$ MFA officially initiates consultations on Romania's initiative to create an International Court to combat terrorism, Press Release. Disponible en https://www.mae.ro/en/node/31628 (Consultado el 21 de julio de 2017). 
ter terrorism, including the phenomenon of Foreign Terrorist Fighters, in line with obligations under international law» ${ }^{4}$.

La propuesta de un Tribunal Internacional contra el Terrorismo (en adelante, TIT) hunde sus raíces en los proyectos de convenio de lucha contra el terrorismo elaborados en 1937 por la Sociedad de Naciones 5 . Al contrario que estos proyectos y la propia organización internacional que les dio amparo, la amenaza del terrorismo ha conseguido sobrevivir y evolucionar conforme al mundo globalizado que pretende destruir ${ }^{6}$. Es por ello que «cette internationalisation du terrorisme a elle-même entraîné une internationalisation de la répression et le développement d'un droit pénal international» ${ }^{7}$. Quienes hoy se encargan de resucitar la propuesta afirman que se encuentra en una fase promocional destinada a generar un «brainstorming» que enriquezca resultado final ${ }^{8}$. En este sentido, las siguientes páginas pretenden ser una aportación crítica a este loable proyecto que busca, mediante el reforzamiento del imperio de la ley, reparar el déficit de legitimidad que han creado las medidas adoptadas durante la denominada «war on terror».

Dos preguntas guiarán el presente estudio: ¿cuáles son los principales desafíos a los que se enfrenta la creación de una jurisdicción internacional competente en esta materia? En segundo lugar, y teniendo en cuenta estos retos, ¿sería dicha jurisdicción la «herramienta legal perfecta» en la lucha contra el terrorismo? Tanto

${ }^{4}$ Meeting Of the Ministers of Foreign Affairs And of the Interior held in Madrid on the Occasion of the Special Meeting of the Counter-Terrorism Committee of The United Nations Security Council, 28 de julio de 2015, p. 1. Disponible en: http://www.un.org/en/sc/ctc/docs/2015/Spain_MinisterialMeeting_FTF.pdf (Consultado el 21 de julio de 2017). Esta declaración es un reflejo del llamamiento del Consejo de Seguridad a la adopción de medidas contra los combatientes terroristas extranjeros. Véase Consejo de Seguridad de Naciones Unidas, Resolución 2178 de 24 de septiembre de 2014, Doc. S/RES/2178. Disponible en http://www.un.org/es/comun/docs/?symbol=S/RES/2178\%20(2014) (Consultado el 21 de julio de 2017).

5 Convention for the Prevention and Punishment of Terrorism, League of Nations Official Journal, January 1938, Gèneve, 16 novembre 1937, pp. 22-35; Convention for the Creation of an International Criminal Court, League of Nations Official Journal, January 1938, Gèneve, 16 novembre 1937, pp. 36-65.

${ }^{6}$ SALINAS DE FRÍAS, A. (2016), «Lucha contra el terrorismo internacional: no solo del uso de la fuerza pueden vivir los Estados», Revista Española de Derecho Internacional, Vol. 68, Núm. 2, pp. 229252.

7 GUILlaume, G. (1989), «Terrorisme et droit international», Recueil des cours de l'Académie de droit international, III, t. 215 , p. 325.

8 AURESCU, B. y GÂLEA, I. (2015), «Establishing an International Court Against Terrorism», Revista de Drept Constitutional, Núm. 1, p. 117. Un ejemplo de ello es la conferencia organizada por la Asociación Internacional de Derecho Penal el 16 de febrero de 2017 en Bucarest, en la que miembros de los gobiernos implicados en esta idea intercambiaron perspectivas con distinguidos académicos sobre los antecedentes históricos en el uso de las herramientas del derecho internacional para combatir el terrorismo, el rationale tras la idea de someter el terrorismo a la jurisdicción de un tribunal internacional y los retos a los que se enfrenta. El programa de la conferencia está disponible en:

http://www.penal.org/en/aidp-world-conference-towards-international-court-terrorism-bucharest16-february-2017 (Consultado el 21 de julio de 2017). 
definir los obstáculos existentes como valorar si sería conveniente o no que tal foro conociese de los actos de terrorismo implica adentrarse en complejos aspectos jurídicos y políticos.

Estas páginas tratan aspectos relacionados directamente con el TIT como son la definición del crimen de terrorismo, su naturaleza y las herramientas que se ofrecen desde el derecho internacional penal. El debate en torno a la legalidad del uso de la fuerza contra grupos terroristas no es el objeto principal de estas páginas ${ }^{9}$, aunque será brevemente tratado por el impacto político que tiene en la configuración de un crimen de terrorismo sujeto a una jurisdicción internacional. Una aproximación puramente legal nos daría respuestas demasiado incompletas ${ }^{10}$ que estarían alejadas del entorno o medio material en el que se desarrollan los esfuerzos en la lucha contra el terrorismo ${ }^{11}$. En este trabajo se analizan las dimensiones jurídicas y políticas para lograr un mejor conocimiento y comprensión de los problemas planteados.

Los elementos que informan la propuesta de un TIT ya han sido en gran parte analizados y discutidos en el marco de proyectos anteriores, por lo que es fácil predecir cuáles serán los puntos fricción. Este artículo sigue dos vías: una descriptiva de los elementos clave de la propuesta; y una evaluadora que permite realizar aportaciones críticas. Con una aproximación inductiva se alcanzan, a partir de los datos concretos de la propuesta y sus posibles debilidades, las conclusiones generales sobre la idoneidad del TIT como una herramienta perfecta para combatir este fenómeno y la existencia de un consenso general suficiente para que vea la luz.

9 Entre la abundante bibliografía al respecto pueden mencionarse, sin ánimo de exhaustividad, GUILLAUME, cit. supra, pp. 405-406; WILMSHURST, E. (2005), «Principles of International Law on the Use of Force by States in Self-Defence», Chatham House Working Papers; SCHRIJVER, N. y VAN DEN HERIK, L. (2010), «Leiden Policy Recommendations on Counter-terrorism and International Law», Netherlands International Law Review, Vol. 57, Núm. 3, pp. 531-550; CORTEN, O. (2012), The Law Against War: The Probibition on the Use of Force in Contemporary International Law, Oxford, Hart Publishing, pp. 174-186; BETHLEHEM, D. (2012), «Self-Defense against an Imminent or Actual Armed Attack by Nonstate Actors», American Journal of International Law, Núm. 106, p. 770; TRAPP, K.N. (2015), «Can Non-State actors mount an Armed Attack?», en WELLER, M., The Use of Force in International Law, Oxford, Oxford University Press, pp. 679-698, pp. 679 y 696; TSAGOURIAS, N. (2016), «Self-Defence against Non-state Actors: The Interaction between Self-Defence as a Primary Rule and Self-Defence as a Secondary Rule», Leiden Journal of International Law, Núm. 29, pp. 801-825, pp. 804-808.

${ }^{10}$ LACHS, M. (1982), The Teacher in International Law, The Hague, Martinus Nijhoff Publishers, p. 155 .

11 ORTIZ ARCE, A. (1980), «Consideraciones metodológicas en Derecho Internacional Público, I y II», Revista de la Facultad de Derecho de la Universidad Complutense, Vol. 61, pp. 67-94; SLAUGHTERBURLEY, A-M. (1993), «International Law and International Relations Theory: A Dual Agenda», The American Journal of International Law, Vol. 87, Núm. 2, pp. 205-239. Para un reciente estudio de la aplicación de la metodología jurídica y política al caso concreto del terrorismo véase FELIU MARTÍNEZ, L. (2017), «El concepto de terrorismo en España y la Unión Europea. Implicaciones para el Derecho», en ALCAIDE FERNÁNDEZ, J. y PETIT DE GABRIEL, E.W., España y la Unión Europea en el Orden Internacional, Valencia, Tirant Lo Blanch, pp. 499-521.

N.o 103, septiembre-diciembre 2018, págs 407-438 


\section{2. ¿QUÉ ACTOS JUZGAR? DEFINICIÓN Y NATURALEZA DEL CRIMEN DE TERRORISMO}

\subsection{La eterna búsqueda de la definición del terrorismo}

La piedra angular con la que se tropieza esta propuesta es la indefinición del crimen de terrorismo ${ }^{12}$, una «cruz familiar» del derecho internacional que en este ámbito se caracteriza por ser «an unsystematic hodge-podge of treaties concerning specific modes of terrorism» ${ }^{13}$. Esta aproximación enumerativa se caracteriza por prohibir el actus reus (los elementos objetivos del crimen, en este caso los actos contenidos en los distintos tratados sectoriales) sin tener en cuenta, por lo general, el mens rea (el elemento subjetivo del crimen o intención) ${ }^{14}$. En este apartado se examinan cuáles son los elementos del crimen, cómo han sido esbozados por las fuentes que inspiran el TIT y las problemáticas que plantean. Con vistas a una mayor claridad en la estructura del discurso, el debate sobre la naturaleza transnacional o internacional del crimen es tratada de forma separada en el siguiente apartado.

Para quienes deseen adentrarse en la ardua tarea de definir el terrorismo, BASSIOUNI propone tres opciones metodológicas: una definición general (i), una selección de actos concretos formulados de manera que contengan la intención específica del comportamiento que busca prohibirse (ii); y una fórmula mixta que combine una

12 Así lo reconocen sus promotores en AURESCU, «Establishing an International Court...», cit. supra, p. 117.

13 GOLDSTONE, R.J. y SIMPSON, J. (2003), «Evaluating the Role of the International Criminal Court as a Legal Response to Terrorism», Harvard Human Rights Journal, Vol. 16, pp. 13-26, p. 13. Los tratados universales existentes hasta la fecha incluyen el Convenio sobre las infracciones y ciertos otros actos cometidos a bordo de las aeronaves (Convenio de Tokio de 1963); Convenio para la represión y el apoderamiento ilícito de aeronaves (Convenio de La Haya de 1970) y su Protocolo Adicional de Beijing de 2010 (aún no entrado en vigor); el Convenio para la represión de actos ilícitos contra la Seguridad de la Aviación Civil (Convenio de Montreal de 1971) y su Protocolo Adicional de 1988; la Convención de para la prevención y castigo contra personas internacionalmente protegidas, inclusive los agentes diplomáticos, 1973; la Convención internacional contra la toma de rehenes, 1979; la Convención de 1980 sobre la protección física de los materiales nucleares y su Protocolo de enmienda de 2005; el Convenio de 1988 para la represión de actos ilícitos contra la seguridad de la navegación marítimay su Protocolo Adicional de 2005; el Protocolo de 1988 para la represión de actos ilícitos contra la seguridad de las plataformas fijas emplazadas en la plataforma continental y su Protocolo Adicional de 2005; el Convenio Internacional sobre la marcación de explosivos plásticos para los fines de detección, 1988; el Convenio Internacional para la represión de actos terroristas cometidos con bombas, 1977; el Convenio internacional para la represión de la financiación del terrorismo, 1999; el Convenio internacional para la represión de los actos de terrorismo nuclear, 2005. Para una contextualización de cada uno de estos instrumentos véase SALINAS DE FRÍAS, A. (2006), "La práctica convencional multilateral de los Estados en materia de cooperación judicial internacional contra el terrorismo», Anuario Argentino de Derecho Internacional, pp. 69-105.

14 GREVE, H.S. (2003), «Acts of terrorism and crimes within the jurisdiction of the International Criminal Court», en BERGSMO M. (ed.), Human Rights and Criminal Justice for the Downtrodden: Essays in Honour of Asbjorn Eide, Leiden, Marinus Nijhoff Publishers, pp. 75-110, p. 104. 
declaración genérica con algunas aplicaciones ilustrativas de contenido específico que muestren la conducta prohibida (iii) ${ }^{15}$. El autor apuesta decididamente por la descripción de actos específicos con un contenido bien definido ${ }^{16}$. Su justificación para desechar las definiciones generales se basa en el principio de legalidad que en la rama penal se plasma en nulla poena sine lege, nullum crima sine lege y la prohibición de normas penales ex post facto ${ }^{17}$. Un precepto penal genérico que requiriese una interpretación analógica sería contrario a estos principios e implicaría el desconocimiento de las conductas prohibidas y la imposibilidad de cumplir con los mandatos legales ${ }^{18}$.

Los promotores del TIT, plenamente conscientes de este obstáculo, defienden la existencia en el derecho consuetudinario de suficientes elementos «que permiten la determinación de un crimen de terrorismo como objeto de la jurisdicción de un futuro tribunal internacional» ${ }^{19}$. La definición estaría formada por dos elementos: «(i) los actos recogidos en las convenciones de lucha contra el terrorismo de Naciones Unidas; y (ii) una definición general abierta, basada en los elementos reconocidos por el derecho internacional consuetudinario y la jurisprudencia: la existencia de intención criminal en la perpetración del acto (dolus), la intención específica de causar terror o coercer a una autoridad (dolus specialis), la perpetración del acto criminal y, cuando sea aplicable, la gravedad de los actos que puedan constituir una amenaza a la paz y seguridad internacionales» ${ }^{20}$.

La definición en dos niveles que se propone para el TIT se asemeja a esa fórmula mixta acusada de ser contraria a los principios del derecho penal. Se mantiene una definición general abierta (que contiene el mens rea) y una lista de actos de terrorismo que no es meramente ilustrativa (actus reus), sino que se limita a los actos contemplados en las convenciones de Naciones Unidas correspondientes. ¿Es nueva esta perspectiva? Un análisis completo de los infructuosos intentos para definir del terrorismo

${ }^{15}$ CHERIF BASSIOUNI, M., (1974) «Methodological Options for International Legal Control of Terrorism», Akron Law Review, Vol. 7, Núm. 3, pp. 388-396, p. 389.

16 Véase ibid, p. 389.

17 Véase ibid, p. 389.

18 Véase ibid, p. 389. Otros autores precisan que el principio ex post facto procedente de las tradiciones constitucionales se aplica de forma distinta al derecho internacional, ya que el primero no es producto de una sola norma sino de un conjunto de instrumentos convencionales, decisiones judiciales y costumbres que han recibido la aceptación o aquiescencia internacional. La aplicación de este principio en el derecho internacional vendría a requerir que «no proof before conviction that the accused knew or should have known that in matters of international concern he was guilty of participation [...] and that he knew or should have known that he would be subject to punishment if caught». Véase CASSESE, A., ACQUAVIVA, G., FAN, M. y WHITING, A. (2011), International Criminal Law: Cases and Commentary, Oxford, Oxford University Press, p. 163. Para un estudio de las tendencias jurisprudenciales en torno al principio de legalidad penal en el ámbito internacional véase MARTÍN MARTÍNEZ, M. (2009), «La Configuración del Principio de Legalidad Penal en el Derecho Internacional Contemporáneo», en CUERDA RIEZU, A. y JIMÉNEZ GARCÍA, F., Nuevos desafíos en el Derecho Penal Internacional: Terrorismo, crimenes internacionales y derechos fundamentales, Madrid, Tecnos, pp. 371-409.

19 AURESCU, «Establishing an International Court...», cit. supra, p. 116.

20 Véase ibid, p. 116.

N.o 103 , septiembre-diciembre 2018, págs 407-438 
a nivel internacional excede con creces los límites de este trabajo. Este estudio se centra en las dos fuentes mencionadas por los promotores de esta propuesta: las convenciones de la Sociedad de Naciones de 1937 y la jurisprudencia del Tribunal Especial para el Líbano.

En efecto, fue en la sede de la extinta Sociedad de Naciones donde se aprobó el primer instrumento que contempla una jurisdicción internacional expresamente competente para conocer de estos crímenes ${ }^{21}$. Un logro que se apoyaba en los hombros de otro aún mayor: la criminalización de los actos de terrorismo. Inicialmente, la Sociedad de Naciones consideró que las normas de derecho internacional relativas a la represión de actividades terroristas no eran lo suficientemente precisas como para garantizar una cooperación internacional eficiente ${ }^{22}$. Para remediar esta insuficiencia, se decidió crear un Comité Internacional para la Represión del Terrorismo (en adelante, CIRT) con el objetivo de redactar «el borrador preliminar de una convención internacional para asegurar la represión de las conspiraciones o crímenes cometidos con un propósito político» ${ }^{23}$.

${ }^{21}$ La propuesta de elaborar un convenio para la criminalización del terrorismo a nivel universal no partió directamente de la Sociedad de Naciones, sino del gobierno rumano con el respaldo del célebre penalista Vespasian Pella. Incluso fue inicialmente rechazada por esta misma organización. Para que viese la luz habría que esperar a los desgraciados acontecimientos del 9 de octubre de 1934, fecha en que fueron asesinados en Marsella el rey Alejandro I de Yugoslavia, el Ministro de Asuntos Exteriores francés Louis Barthou y dos oficiales que intentaron evitar el suceso. La tensión diplomática en torno los cuatro Estados afectados (Hungría, Yugoslavia, Italia y Francia) proyectaba la sombra del tristemente célebre atentado de Sarajevo y de las consecuencias que éste tuvo en la historia mundial. La gravedad de la situación llevó a la Sociedad de Naciones a reintroducir la amenaza del terrorismo en su agenda. Esta vez fue el gobierno francés el que inició un ciclo de debates en el Consejo de la Sociedad de Naciones sobre la necesidad de adoptar un convenio internacional para la represión del terrorismo. El registro que se tiene de los primeros debates en el Consejo de la Sociedad de Naciones muestra un fuego cruzado de acusaciones en torno al uso del terrorismo por ciertos Estados como instrumento político. Hasta tal punto que el delegado británico solicitó que «if we are to preserve the cause of peace, we must seggregate the domain of facts from that of motives and of policy. A difficult situation must not be further embittered. Existing anomousities must not be further provoked». Para un análisis más detallado de estas convenciones y el contexto en que se desarrollaron véanse SOTTILE, A. (1938), «Le Terrorisme International», Recueil des cours de l'Académie de droit international, III, t. 65, pp. 91-178; y DONNEDIEU DE VABRES, H. (1938), «La répression internationale du terrorisme: Les conventions de Gèneve (16 novembre 1937)», Revue de Droit International et de Législation comparée, Vol. 19, pp. 37-74.

${ }^{22}$ League of Nations Official Journal, December 1934, Sixth Meeting of the Council, December 10th 1934, p. 1760.

${ }^{23}$ Véase ibid. El anteproyecto de convenio preparado por el CIRT constaba en sus inicios de dos apartados. El primero de ellos dedicado a la represión del terrorismo, y el segundo a la organización y funcionamiento de una corte penal internacional. La criminalización del terrorismo y su sometimiento a una jurisdicción internacional eran dos conceptos que iban de la mano en una única convención y que los Estados debían aceptar en bloque. Tras las observaciones presentadas por los gobiernos al primer borrador, se decidió dividirlo en dos convenciones distintas: una primera para la prevención y represión del terrorismo, y una segunda para la creación de una corte penal internacional. Esta solución permitía que la primera convención fuese ratificada por aquellos Estados contrarios a esta jurisdicción. Y, lógicamente, quienes desearan incorporarse a la corte debían ratificar esa primera convención que recogía su jurisdicción ratione materiae. Para un análisis doctrinal sobre la decisión de dividir la convención véase RAMÓN CHORNET, C. (1992), Terrorismo y respuesta de fuerza en el marco del Derecho Internacional, Valencia, Tirant lo Blanch, p. 51. 
El resultado de los tres años de trabajo del CIRT fue objeto de una Conferencia Intergubernamental convocada por el Consejo de la Sociedad de Naciones en Ginebra $^{24}$. El 16 de noviembre de 1937 fueron aprobadas dos convenciones que seguían muy de cerca los trabajos del CIRT $^{25}$. Aunque sólo la India ratificase la primera convención y ningún Estado apostase finalmente por la Corte, no por ello deben excluirse automáticamente las aproximaciones que allí se realizaron ${ }^{26}$. De hecho, allí se sembró la semilla de avances que se realizaron con posterioridad, y que continúan en nuestros días, en la lucha contra el terrorismo internacional ${ }^{27}$.

El primer artículo define genéricamente los actos terroristas como «des faits criminels dirigés contre un Etat et dont le but ou la nature est de provoquer la terreur chez des personnalités déterminées, des groupes de personnes ou dans le public». A continuación, el art. 2 recoge una lista de actos que deben ser considerados como terroristas en los ordenamientos internos. En ella se incluyen los atentados cometidos contra determinadas personas, así como contra bienes públicos, sin olvidar el grado de tentativa ${ }^{28}$.

Por su parte, el art. 3 criminaliza cualquier tipo de acto que, aun sin suponer una intervención activa en la comisión de atentados, sí contribuya a que éstos se produzcan. Se incluyen como delitos la asociación, la participación, la instigación que haya provocado efectos, la instigación directa y pública pese a que no haya sido seguida de un efecto, así como cualquier otro tipo de ayuda destinada a favorecer la comisión de los actos enumerados en el art. 2.

${ }^{24}$ League of Nations Official Journal, May-June 1937, Fifth Meeting of the Council, May 27th 1937, pp. 308-310.

${ }_{25}$ Convention for the Prevention and Punishment of Terrorism, cit supra; Convention for the Creation of an International Criminal Court, cit. supra.

${ }^{26}$ GROSS, L. (1973), «International Terrorism and International Criminal Jurisdiction», The American Journal of International Law, Vol. 67, Núm. 3, pp. 508-511, p. 508.

27 RABBAT, P.J., "The Role of the United Nations in the Prevention and Repression if International Terrorism», en WADE, M. y MALJEVIC, A. (eds.), A War on Terror? The European Stance on a New Threat, Changing Laws and Human Rights Implications, Springer Sciences and Busines Media, 2010, pp. 81-106, p. 83

28 El art. 2 del texto original condena así:

«1. Les faits intentionnels dirigés contre la vie, l'intégrité corporelle, la santé ou la liberté:

Des chefs d'Etat, des personnes exerçant les prérogatives du chef d'Etat, de leurs successeurs héréditaires ou désignés;

Des conjoints des personnes ci-dessus énumérées;

Des personnes revêtues de fonctions ou de charges publiques lorsque ledit fait a été commis en raison des fonctions ou charges que ces personnes exercent.

2. Le fait intentionnel consistant à détruire ou à endommager des bien publics destines à un usage public qui appartiennent à une autre Haute Partie contractante ou qui relèvent d'elle.

3. Le fait intentionnel de nature à metre en peril des vies humaines par la création d'un danger commun.

4. La tentative de commettre les infractions prévues par les dispositions ci-dessus du présent article.

5. Le fait de fabriquer, de se procurer, de détenir ou de fournir des armes, munitions, produits explosifs ou substances nocives en vue de l'exécution, en quelque pays que ce soit, d'une infraction prévu par le présent article». 
De un lado, la definición genérica de terrorismo (mens rea). De otro, la lista de actos que deben ser considerados como terroristas (actus reus). Una lectura integral de ambos preceptos muestra cuáles eran, a efectos de la Convención, las condiciones para que un acto fuese catalogado como terrorista ${ }^{29}$ :

a) Actos criminales.

b) Dirigidos contra un Estado.

c) Cuyo fin o naturaleza sea la de provocar terror.

d) Terror que debe ser provocado en personalidades determinadas, grupos de personas o el público.

e) Que deben estar catalogados en los arts. 2 y 3, ya se trate de autoría o de participación.

f) Y que deben revestir un carácter internacional. Ello puede darse por diversos factores: refugio del autor o de sus cómplices en un Estado parte distinto a aquel en que se prepararon y cometieron los atentados; por los lugares preparación, perpretración y efectos del acto; la nacionalidad del autor o de sus cómplices; la naturaleza de los intereses lesionados o que el Estado contra el que se dirija el acto sea distinto a aquel en el cual se comete.

Como indica SAUL, lo primero que destaca de la definición es que su mens rea omite los motivos políticos y los objetivos de coerción que habían dado sentido a la creación del CIRT $^{30}$. Los intentos por incluir el terrorismo como un medio para conseguir un fin político fueron rechazados, de modo que el mens rea del crimen de terrorismo quedaba tautológicamente definido por referencia a la ambigua expresión de «provocar terror» ${ }^{31}$. A ello se suma que en el actus reus sólo eran considerados como terroristas los actos dirigidos contra el Estado, excluyendo así los cometidos contra particulares ${ }^{32}$.

Por otro lado, el impacto de la jurisprudencia del Tribunal Especial para el Líbano (en adelante, TEL) en esta propuesta es evidente ${ }^{33}$. En su famosa decisión sobre el atentado cometido en Beirut que se cobró la vida de 22 personas, incluida la del ex primer ministro Rafik Hairiri, la Cámara de Apelaciones identificó tres elementos claves para la definición de terrorismo a nivel internacional: «(i) la perpetración de un acto criminal (tales como el asesinato, el secuestro, la toma de rehenes o la provocación de incendios), o la amenaza de realizar tales actos; (ii) la intención de extender el miedo entre la población (que generalmente supondría la creación de un peligro

\footnotetext{
29 SOTTILE, cit. supra, pp. 123-126.

${ }^{30}$ SAUL, B., «Attemps to Define Terrorism in International Law», Netherlands International Law Review, Vol. 52, Núm. 1, 2005, pp. 57-83, pp. 64.

${ }^{31}$ Véase ibid, p. 64.

${ }^{32}$ Véase ibid, p. 64.

33 AURESCU, B. «Towards and International Court Against Terrorism?, discurso pronunciado el 16 de febrero de 2017 durante la conferencia organizada por la Asociación Internacional de Derecho Penal en Bucarest. Disponible en:

http://www.mae.ro/sites/default/files/file/anul_2017/2017.02.16_keynote_intervention_bogdan_aurescu.pdf (Consultado el 21 de julio de 2017)
} 
público) o directa o indirectamente coercer a una autoridad nacional a internacional a realizar alguna acción, o a abstenerse de realizarla; (iii) la presencia de elementos transnacionales en el acto» ${ }^{34}$. Estas conclusiones, basadas en una amplia amalgama de fuentes nacionales e internacionales ${ }^{35}$, han sido objeto de crítica por diversas razones ${ }^{36}$. AMBOS, autor al que se refiere la propia decisión por haber revisado los instrumentos universales y regionales existentes en materia de terrorismo ${ }^{37}$, es uno de los primeros en expresar sus dudas sobre los elementos del crimen de terrorismo que se contienen en este pronunciamiento ${ }^{38}$.

En lo relativo al actus reus, la Cámara reconoce que basa su definición en que cualquier libanés podía prever «que cualquier acto destinado a extender el terror sería sancionable, independientemente del tipo de instrumentos empleados ${ }^{39}$. Dado que la legislación nacional no tipificaba como terroristas los actos cometidos con cuchillos y armas de fuego en esas circunstancias, la Cámara argumenta que la ratificación por Líbano de las convenciones de la ONU sobre terrorismo permite hacer analogías en cuanto a la conducta punible del actor pues éste sabe que ${ }^{40}$ «disparar (o amenazar con disparar) a pasajeros a bordo de una aeronave con el propósito de secuestrarla constituye un acto prohibido de terrorismo, y que puede ser concluido con seguridad que la misma conducta con la misma intención de extender el miedo en otras circunstancias (por ejemplo, en una calle abarrotada) también sería considerada como terrorismo» ${ }^{41}$. El problema, tal y como indica SAUL, es que ninguna de las convenciones actuales contempla los actos cometidos con instrumentos tan habituales hoy día como los cuchillos y las armas de fuego ${ }^{42}$.

Las fuentes pertinentes coinciden en un único elemento objetivo común: «la comisión, incluida la amenaza concreta, de un acto criminal», a lo que se suman ciertas

34 Tribunal Especial para el Líbano, Interlocutory Decision on the Applicable Law: Terrorism, Conspiracy, Homicide, Perpetration, Cumulative Charging, 16 de febrero de 2011, Case No. STL-11/01/I, pár. 85. Un estudio completo de la labor de este tribunal es el recogido en ALAMUDDIN, A., NABIL, N. y TOLBERT, D. (eds. 2014), The Special Tribunal for Lebanon: Law and Practice, Oxford, Oxford University Press.

35 Para una postura que considera totalmente errónea la valoración que hace el tribunal de estas fuentes véase SAUL, B. (2011) «Legislating from a Radical Hague: The United Nations Special Tribunal for Lebanon Invents an International Crime of Transnational Terrorism», Leiden Journal of International Law, Vol. 24, Núm. 3, pp. 677-700.

36 Aunque aquí se centra la atención únicamente en los elementos del crimen, en el siguiente apartado se analizará la decisión con respecto a la naturaleza de crimen internacional del delito.

37 Véase Interlocutory Decision on the Applicable Law: Terrorism, Conspiracy, Homicide, Perpetration, Cumulative Charging, cit. supra, pár. 84.

38 AMBOS, K. (2012), «Creatividad Judicial en el Tribunal Especial para el Líbano: ¡es el terrorismo un crimen internacional», Revista de Derecho Penal y Criminología, Vol. 3, Núm. 7, pp. 143-173.

39 Véase Interlocutory Decision on the Applicable Law: Terrorism, Conspiracy, Homicide, Perpetration, Cumulative Charging, cit. supra, pár. 138.

40 AMBOS, «Creatividad Judicial en el Tribunal Especial para el Líbano...», cit. supra, p. 154.

41 Véase Interlocutory Decision on the Applicable Law: Terrorism, Conspiracy, Homicide, Perpetration, Cumulative Charging, cit. supra., pár. 141.

42 SAUL, «Legislating from a Radical Hague...», cit. supra, p. 687. 
convenciones que criminalizan actos específicos de terrorismo ${ }^{43}$. El problema es que la generalidad de esta regla hace que sea difícilmente compatible con el requisito de lex certa del principio de legalidad ${ }^{44}$. Incluso la expresión final «and so on» al final de la lista ilustrativa de actos añade un tono más de vaguedad y deja la puerta abierta a una interpretación expansiva del actus reus ${ }^{45}$. La fórmula es por tanto acusada de ser incompatible con la regla nullum crimen, que sólo permite la interpretación ex post facto o la analogía cuando sea in bonam partem ${ }^{46}$. Una definición, en suma, que recuerda a la tercera opción rechazada por BASSIOUNI varios años antes por estos mismos motivos.

En cuanto al mens rea, tampoco la decisión del TEL está exenta de polémica. La definición distingue entre la intención de extender el miedo entre la población (intención especial «general») y el propósito de coaccionar a un Estado u organización internacional a hacer o abstenerse de hacer algo (intención especial «especial» ${ }^{47}$. Esta última intención, que «derivará o estará fundamentada frecuentemente en propósitos políticos o ideológicos subyacentes» ${ }^{48}$, genera dos problemas.

El primero de ellos, presente desde las convenciones de 1937, es que «este aspecto del crimen de terrorismo todavía no ha sido configurado y aceptado tan amplia y de forma tan consistente como para alcanzar el nivel de derecho consuetudinario» ${ }^{49}$. $\mathrm{Y}$, en segundo lugar, porque más que una intención se trata de una motivación (la razón por la cual un autor realiza el acto, que en este caso diferenciaría entre el terrorista que persigue un objetivo político y el que persigue un objetivo criminal común bajo la apariencia de una agenda política $)^{50}$. Sin entrar demasiado en la cuestión de si la motivación debe ser parte de la definición del crimen o si es una circunstancia modificativa de la responsabilidad criminal, lo cierto es que poderes legislativos supranacionales como la UE incluyen como parte del delito el fin de «obligar indebidamente a los poderes públicos o a una organización internacional a realizar un acto o abstenerse de hacerlo» ${ }^{51}$.

¿Son aplicables las críticas anteriores a la definición que se propone para el TIT? En cuanto al actus reus, pueden ser superadas ya que se limita a los actos específicos

43 AMBOS, «Creatividad Judicial en el Tribunal Especial para el Líbano...», cit. supra, p. 168.

44 Véase ibid., p. 153.

45 GILLET, M. Y SCHUSTER, M. (2011), «Fast-track Justice: The Special Tribunal for Lebanon Defines Terrorism», Journal of International Criminal Justice, Vol. 9, pp. 989-1020, pp. 1009-1010.

46 AMBOS, «Creatividad Judicial en el Tribunal Especial para el Líbano...», cit. supra, p. 155.

47 Aunque esta no es la terminología empleada directamente por el TEL, es comúnmente empleada por la doctrina en esta materia. Véase WILMSHURST, E. (2010) «Transnational Crimes, Terrorism and Torture», en CRYER, R., FRIMAN, H., ROBINSON, D. y WILMSHURST, E. (eds.), An Introduction to International Criminal Law and Procedure, Cambridge, Cambridge University Press, p. 347.

48 Véase Interlocutory Decision on the Applicable Law: Terrorism, Conspiracy, Homicide, Perpetration, Cumulative Charging, cit. supra, pár. 106.

49 Véase ibid, pár. 106.

50 AMBOS, «Creatividad Judicial en el Tribunal Especial para el Líbano...», cit. supra, p. 172.

51 Art. 3 de la Directiva (UE) 2017/541 del Parlamento Europeo y del Consejo de 15 de marzo de 2017 relativa a la lucha contra el terrorismo y por la que se sustituye la Decisión marco 2002/475/JAI del Consejo y se modifica la Decisión 2005/671/JAI del Consejo, DOUE L 88/6. 
contenidos en las convenciones de la ONU. Si bien esta fundamentación en los convenios ya existentes facilitaría un mayor consenso entre los Estados a la hora de adoptar la propuesta, en aras de la eficacia podrían incluirse otros actos específicos tales como los cometidos con armas de fuego y cuchillos. En todo caso, parece que ya existe acuerdo en considerar los actos cometidos contra particulares como crímenes de terrorismo, y no sólo los cometidos contra autoridades públicas. Con respecto al mens rea, aunque es posible que la definición no encuentre consenso suficiente por incluir esa influencia en las decisiones de una autoridad nacional o internacional por motivos políticos o ideológicos, lo cierto es que es su presencia tiene en cuenta la compleja fenomenología del terrorismo y ayuda a evitar lo que en caso contrario serían definiciones demasiado amplias ${ }^{52}$.

\subsection{Crimen internacional vs crimen transnacional}

Una vez identificados los elementos del crimen de terrorismo y la problemática que generan, el siguiente paso consistiría en determinar si el terrorismo tiene o no la naturaleza de «crimen internacional» que le permitiría traspasar los límites de las jurisdicciones nacionales y quedar sometido a un tribunal supranacional. Pero antes de entrar en este análisis es importante recordar que, en la terminología anglosajona, el concepto de international criminal law aúna los aspectos internacionales del derecho penal (crímenes tipificados en los ordenamientos domésticos que tienen una dimensión internacional) y los aspectos criminales del derecho internacional (crímenes contra los valores fundamentales de la comunidad internacional) ${ }^{53}$. Una distinción que en las lenguas románicas, y en concreto la española, se plasma en los conceptos de derecho penal internacional (como rama del derecho penal que tiene en cuenta la presencia de elementos extranjeros) y derecho internacional penal (como rama del derecho internacional con un objetivo específicamente penal) con la importancia que esto supone en la aplicación de los principios y normas propios de cada rama ${ }^{54}$.

El primer aspecto (derecho penal internacional) se centra en los crímenes transnacionales basados en «convenciones para la represión», tales como la Convención contra la Tortura o el Convenio Internacional para la Represión de actos terroristas cometidos con bombas, sobre los que sólo son competentes para conocer las jurisdic-

52 AMBOS, K. y TIMMERMANN, A. (2014), «Terrorism and customary international law», en SAUL, B. (ed.), Research Handbook on International Law and Terrorism, Cheltenham, Edward Elgar Publishing, pp. 20-38, p. 35.

53 CHERIF BASSIOUNI, M. (1983), «The Penal Characteristics of Conventional International Criminal Law», Case Western Reserve Journal of International Law, Vol. 15, Núm. 1, pp. 27-37, p. 27.

54 RODRÍGUEZ CARRIÓN, A.J. (2005), «Derecho Internacional Penal y Derecho Penal Internacional», en GONZÁLEZ CAMPOS, J.D. (hom.), Pacis Artis: Obra Homenaje al Profesor Julio D. González Campos, Madrid, Eurolex, Tomo I, pp. 563-587, pp. 575 y 580. Véase también GIL GIL, A. y MACULAN, E. (2016), «Qué es el Derecho Penal Internacional», en GIL GIL, A. y MACULAN, E. (eds.), Derecho Penal Internacional, Madrid, Dykinson, p. 37. 
ciones nacionales ${ }^{55}$ y que necesitan de cooperación internacional para su supresión ${ }^{56}$. Por su parte, el segundo que aquí nos interesa (derecho internacional penal) genera crímenes internacionales «auténticos» que imponen obligaciones sobre los individuos y la correlativa obligación de instituciones supranacionales y Estados de hacerlas cumplir, independientemente de si son actos criminalizados a nivel nacional y de los vínculos de jurisdicción tradicionales ${ }^{57}$. El caso más ilustrativo es el de los crímenes contenidos en los arts. 5 a 8 del Estatuto de Roma, si bien no son los únicos ${ }^{58}$.

De hecho, la idea de incluir el terrorismo como crimen internacional ha sido recibida en varias ocasiones en el seno del Estatuto de Roma, pero nunca invitada a quedars $^{59}$. El gobierno estadounidense expresó sus dudas antes incluso de que se celebraran las primeras reuniones del Comité Preparatorio ${ }^{60}$. Entre ellas cabe destacar el riesgo de politización de la Corte, la posibilidad de que esta jurisdicción obstaculizase los procedimientos criminales domésticos y bilaterales y que la intervención de su fiscal jugase como un «escudo a la efectiva aplicación de la ley» dada la alta sensibilidad de la información implicada en los casos de terrorismo y la necesidad de tomar decisiones rápidas ${ }^{61}$. A ello se sumaba que la Corte no tendría medios suficientes para perseguir unos crímenes que, en todo caso, ni siquiera estaban dotados de una definición precisa a nivel internacional ${ }^{62}$.

El Proyecto de Estatuto de Roma acabó por incluir el crimen de terrorismo entre paréntesis, una gráfica expresión del fracaso en superar las discrepancias existentes ${ }^{63}$. Con el añadido, según palabras del propio Comité Preparatorio, de la falta de tiempo

55 WILMSHURST, «Transnational Crimes...» cit supra, pp. 335-336. En la misma línea GAETA, P. (2009), «International Criminalization of Prohibited Conduct», en CASSESE, A., The Oxford Companion to International Criminal Justice, Oxford, Oxford University Press, pp. 63-74, p. 63.

56 CREEGAN, E. (2011), «A Permanent Hybrid Court for Terrorism?», American University International Law Review, Vol. 26, Núm .2, pp. 239-311, pp. 245-246.

57 AMBOS. K. (2013), «Punishment without a Sovereign? The Ius Puniendi Issue of International Criminal Law: A First Contribution towards a Consistent Theory of International Criminal Law», Oxford Journal of Legal Studies, Vol. 33, Núm. 2, pp. 293-315.

58 El propio Estatuto de Roma en su art. 22.3 prevé que «nada de lo dispuesto en el presente artículo afectará a la tipificación de una conducta como crimen de derecho internacional independientemente del Estatuto». Para un análisis de esta disposición véase WERLE, G. y JESSBERGER, F. (2014), Principles of International Criminal Law, Oxford, Oxford University Press, pp. 31-32.

59 Para un estudio completo al respecto véase ARNOLD, R. (2004), The ICC as a New Instrument for Repressing Terrorism, Nueva York, Transnational Publishers.

${ }^{60}$ Comité Especial sobre el Establecimiento de una Corte Penal Internacional, Comentarios recibidos de conformidad con el párrafo 4 de la Resolución 49/53 de la Asamblea General relativa al establecimiento de una Corte Penal Internacional, de 31 de marzo de 1995, Doc. A/AC.244/1/Add. 2. Disponible en https://documents-dds-ny.un.org/doc/UNDOC/GEN/N95/093/90/pdf/N9509390. pdf?OpenElement (Consultado el 21 de julio de 2017).

61 Véase ibid., párs. 27-29.

62 Véase ibid., párs. 37-45.

63 VAN DER VYVER, J.D. (2010), «Prosecuting Terrorism in International Tribunals», Emory International Law Review, Vol. 24, pp. 527-547, p. 537. 
suficiente para examinar este crimen ${ }^{64}$. La propuesta final recoge una lista de actos considerados crímenes de terrorismo conforme a las convenciones sectoriales existentes en la materia, «cualesquiera sean los motivos y propósitos que se hagan valer para justificarlos, ya sean éstos de índole política, filosófica, ideológica, racial, étnica o religiosa o de naturaleza similar» ${ }^{65}$.

Para vencer la resistencia de aquellos Estados que temían abrir la caja de Pandora de la definición del crimen, el estatus de los movimientos de liberación nacional y la cuestión del terrorismo estatal $^{66}$, varios plenipotenciarios propusieron incluir terrorismo en la jurisdicción de la Corte Penal Internacional bajo la rúbrica de «crímenes de lesa humanidad ${ }^{67}$, en línea con Proyecto de Ofensas contra la Paz y la Seguridad de la Humanidad presentada por la Comisión de Derecho Internacional en $1995^{68}$.

La propuesta anterior tuvo poca acogida, por lo que estos mismos Estados decidieron centrar sus esfuerzos en una solución similar a la otorgada para el crimen de agresión, es decir, en incluir el crimen de terrorismo en el art. 5 pero dejando el desarrollo de su definición a conferencias futuras ${ }^{69}$. Dado que esta opción tampoco tuvo éxito, tuvieron que conformarse con una Resolución en la que se «recomienda que, en una Conferencia de Revisión, de conformidad con el art. 123 del Estatuto de la Corte Penal Internacional, se examinen los crímenes de terrorismo y los relacionados con las drogas con miras a llegar a una definición aceptable y a que queden comprendidos en la lista de crímenes de la competencia de la Corte» ${ }^{70}$.

${ }^{64}$ Informe del Comité Preparatorio sobre el establecimiento de una Corte Penal Internacional, A/ CONF.183/2/Add.1. 14 de abril de 1998, p. 27. Disponible en https://documents-dds-ny.un.org/doc/ UNDOC/GEN/N98/101/08/pdf/N9810108.pdf?OpenElement (Consultado el 21 de julio de 2017).

65 Véase ibid., p. 27.

${ }^{66} \mathrm{KOLB}, \mathrm{R}$., «The exercise of criminal jurisdiction over international terrorists», en BIANCHI, A. (2004), Enforcing international law norms against terrorism, Oxford, Hart Publishing, pp. 227-281, p. 279.

${ }_{67}$ Propuesta presentada por la India, Sri Lanka y Turquía, A/CONF.183/C.1/L.27/Rev.1, 6 de julio de 1998. Disponible en:

https:/documents-dds-ny.un.org/doc/UNDOC/LTD/G98/712/62/pdf/G9871262.pdf?OpenElement (Consultado el 21 de julio de 2017).

${ }^{68}$ Comisión de Derecho Internacional, Informe sobre la labor realizada en su $46 .^{\circ}$ período de sesiones, del 2 de mayo al 2 de julio de 1994, Doc. A/49/10, art. 20, pp. 50-53. Disponible en https:// documents-dds-ny.un.org/doc/UNDOC/GEN/N94/349/31/img/N9434931.pdf?OpenElement (Consultado el 21 de julio de 2017).

69 Propuesta presentada por Barbados, Dominica, India, Jamaica, Sri Lanka, Trinidad y Tobago y Turquía, 14 de julio de 1998, A/CONF.183/C.1/L.71. Disponible en https://documents-dds-ny.un.org/ doc/UNDOC/LTD/G98/721/88/pdf/G9872188.pdf?OpenElement (Consultado el 21 de julio de 2017).

Véase en la misma línea WERTHEIM, P.J. (2003), «Should Graves Crimes of International Terrorism be included in the Jurisdiction of the International Criminal Court?», Policy and Society, Vol. 22, pp. 1-21, p. 3.

70 Acta Final de la Conferencia Diplomática de Plenipotenciarios de las Naciones Unidas sobre el Establecimiento de una Corte Penal Internacional, 17 de julio de 1998, A/CONF.183/10, Resolución E, p. 8. Disponible en:

https://documents-dds-ny.un.org/doc/UNDOC/GEN/N98/241/88/pdf/N9824188.pdf?OpenElement (Consultado el 21 de julio de 2017). 
Poco después de los atentados del 11 de septiembre de 2001, Turquía volvió a insistir en la necesidad de incluir tal previsión en el Estatuto de Roma. Haciéndose eco de la propuesta turca, la Asamblea Parlamentaria del Consejo de Europa aprobó dos textos en los que consideraba a la CPI «la institución apropiada para lidiar con los actos de terrorismo» ${ }^{71}$, y apelaba a los Estados miembros a dar «consideración urgente a la enmienda y extensión del Estatuto de Roma para permitir que los actos de terrorismo internacional sean remitidos a la Corte Penal Internacional» ${ }^{72}$.

Pero tal y como se había acordado en 1998, hubo que esperar a la primera Conferencia de Revisión para que se volvieran a presentar avances en esta línea. Con vistas a la Conferencia de Kampala que iba a tener lugar en 2010, el gobierno de Países Bajos tomó la iniciativa con una propuesta «para incluir el terrorismo en la lista de crímenes recogidos en el Estatuto. También proponemos posponer el ejercicio de la jurisdicción sobre este crimen hasta que una definición y las condiciones para el ejercicio de la jurisdicción hayan sido acordadas. Además, los Países Bajos proponen que la Conferencia de Revisión establezca un grupo de trabajo informal sobre el crimen de terrorismo» ${ }^{73}$. La propuesta, que intentaba evitar entrar en la definición del terrorismo, recuerda en su comedimiento a la ya presentada por otros Estados en $1998^{74}$. Tampoco fructificó la idea en esta ocasión, por lo que el asunto quedó relegado a sesiones posteriores de la Asamblea de Estados Partes.

Aunque hoy por hoy el terrorismo no está incluido en el Estatuto de forma expresa, no son pocos quienes defienden que «naturalmente, el que los actos de terror no constituyan per se crímenes de lesa humanidad o de guerra a tenor del Estatuto de Roma no será obstáculo a que, en determinados crímenes de lesa humanidad o de guerra, puedan incardinarse aquellos actos de terrorismo que reúnan las condiciones o elementos exigidos para ello» ${ }^{75}$. De este modo, si un atentado terrorista como "par-

\footnotetext{
71 Parliamentary Assembly of the Council of Europe, Resolution 1258, p. 1. Disponible en: http://assembly.coe.int/nw/xml/XRef/Xref-DocDetails-EN.asp?FileID=16943\&lang=EN (Consultado el 21 de julio de 2017).

72 Parliamentary Assembly of the Council of Europe, Recommendation 1534, p. 2. Disponible en: http://assembly.coe.int/nw/xml/XRef/Xref-DocDetails-EN.asp? fileid = 17506\&lang =EN\&search=MTUzNHx0eXBIX3N0c19lbjpSZXNvbHV0aW9u (Consultado el 21 de julio de 2017).

73 The Netherlands- Speech General Debate 8th ASP, The Hague, 19th november 2009.

74 Propuesta presentada por Barbados, Dominica, India, Jamaica, Sri Lanka, Trinidad y Tobago y Turquía, 14 de julio de 1998, A/CONF.183/C.1/L.71. Disponible en https://documents-dds-ny.un.org/ doc/UNDOC/LTD/G98/721/88/pdf/G9872188.pdf?OpenElement (Consultado el 21 de julio de 2017).

75 Pignatelli y Meca, F. (2006), «El terrorismo como crimen de lesa humanidad y crimen de guerra en el Estatuto de Roma de la Corte Penal Internacional», en Lucha contra el terrorismo y Derecho Internacional, Cuadernos de Estrategia, n. ${ }^{\circ}$ 133, Ministerio de Defensa, Madrid, 2006. pp. 195-235, p. 220. Disponible online en: http://bibliotecavirtualdefensa.es/BVMDefensa/i18n/catalogo_imagenes/grupo. cmd?path=27850 (Consultado el 21 de julio de 2017)

Para un análisis detallado de los distintos actos terroristas que pueden caer en el catálogo de crímenes del Estatuto de Roma véase CoHen, A. (2012), «Prosecuting Terrorists at the International Criminal Court: Reevaluating an Unused legal Tool to Combat Terrorism», Michigan State International Law Review, Vol. 20, Núm. 2, pp. 219-257, pp. 239-249.
} 
te de un ataque generalizado o sistemático contra la población civil» ${ }^{76}$ consistiera en uno de los actos incluidos la lista del art. 7 o se tratare de «otros actos inhumanos de carácter similar que causen intencionalmente grandes sufrimientos o atenten gravemente contra la integridad física o salud mental o física ${ }^{77}$, y fuese cometido con tal conocimiento $^{78}$, entonces se podría hablar de un crimen de lesa humanidad ${ }^{79}$.

Un razonamiento similar es el aplicado a los crímenes de guerra. Se defiende así que «if terrorism is resorted to as an instrument of war, it can be prosecuted as, for example, an intentional attack directed against the civilian population as such or against individual civilians not taking direct part in the hostilities. These examples are irrespective of whether the hostilities qualify as an international armed conflict or as an armed conflict not of an international character» ${ }^{80}$. Para GASSER «se puede decir que los actos terroristas que dañan a la población civil o a bienes de carácter civil están manifiestamente prohibidos por el derecho internacional moderno [...] en otros términos: son crímenes de guerra [...]. Según lo establecido por el Estatuto de Roma, esas personas pueden ser sometidas a la jurisdicción de la Corte Penal Internacional. Los actos terroristas cometidos en tiempo de conflicto armado serán juzgados, en la mayoría de los casos, como crímenes de guerra (artículo 8 del Estatuto de Roma), mientras que, en otras situaciones, esos actos pueden ser calificados como crímenes de lesa humanidad (art. 7)» ${ }^{81}$.

Algunos ejemplos concretos dan soporte a esta interpretación extensiva del Estatuto. En el caso del crimen de guerra relativo a la toma de rehenes, la descripción de los Elementos de los Crímenes recoge que «el autor haya tenido la intención de obligar a un Estado, a una organización internacional [...] a que actuaran o se abstuvieran

En referencia a los atentados del 11 de septiembre, el profesor Cassese concluía que «Indeed, that atrocious action exhibits all the hallmarks of crimen against humanity: the magnitude and the extreme gravity of the attack as well as the fact that it targeted civilians, is an affront to all humanity, and part of a widespread or systematic practice». Véase CASSESE, A. (2001), «Terrorism is Also Disrupting some Crucial Legal Categories of International Law», European Journal of International Law, Vol. 12, pp. 9931001, pp. 994-995; así como EL Amine, H. (2008), «Pourquoi la Cour Pénale internationale n’est-elle pas compétente en matière de terrorism international?» en GLennon, M.J. y Sur, S., Terrorism and International Law, Leiden, Nijhoff Publishers, p. 256; CARmona Bermejo, J. (2009), «La Competencia de la Corte Penal Internacional en materia de terrorismo», en Fernández LiesA, C.R. (dir.), Tribunales Internacionales y Espacio Iberamericano, Pamplona, Thomson-Civitans, p. 308; y KIRSCH, P. (2002), «Terrorisme, crimes contre l'humanité et Cour Pénale internationale», en Livre Noir, S.O.S Attentats, pp. 111-123. Disponible en: http://www.sos-attentats.org/publications/Kirsch.pdf (Consultado el 21 de julio de 2017 ).

76 Art. 7.1 del Estatuto de Roma.

77 Art. 7.1.k) del Estatuto de Roma.

78 Art. 7.1 del Estatuto de Roma.

79 Van Ginkel, B. (2009), «How to Repair the Legitimacy Deficit in the War in Terror: A Special Court for Dealing with International Terrorism?», en De ZwaAn, J., Bakker, E. y VAn Der MeEr, S. (eds.), Challenges in a Changing World, The Hague, Asser Press, pp. 145-262, p. 158.

80 VAN DER VYVER, cit. supra, pp. 540-541.

${ }^{81}$ GASSER, H.P. (2002), «Acts of terror, «terrorism» and international humanitarian law», International Review of the Red Cross, Vol. 84, N. ${ }^{\circ} 47$, pp. 547-570, p. 556. 
de actuar como condición expresa o tácita de la seguridad o la puesta en libertad de esa o esas personas» ${ }^{82}$, en una clara referencia a la motivación típica de los grupos terroristas $^{83}$. Además, ya existe una sentencia de la CPI, aunque sea la única hasta la fecha, en la que se condena a un miembro de grupo terrorista, Al-Qaeda, por crímenes de guerra al intervenir en la destrucción de mausoleos calificados como patrimonio cultural de la humanidad (sin mencionar en ningún momento el terrorismo) ${ }^{84}$.

Los argumentos que apoyan esta extensión indirecta de la jurisdicción de la CPI son sin duda meritorios. Pero una vez examinados los esfuerzos previos por incluir el terrorismo en el Estatuto queda a plena vista un importante obstáculo. Tal y como manifiesta CREEGAN, «reading terrorism into another crime's definition would involve exactly the kind of twisting of legal definitions and statutory overreaching that first made states uneasy about the existence of an International Criminal Court. This move would constitute a direct contravention of the will of the negotiating parties who chose to exclude terrorism from the Rome Statute. If we wish to make terrorism a crime under the ICC, then let us explicitly add the crime to the court's jurisdiction» ${ }^{85}$.

Ahora bien, y dado que el Estatuto de Roma no ostenta la exclusividad de los crímenes internacionales, ¿qué elementos forman su idiosincrasia? La doctrina, con algunas variantes, coincide en que deben concurrir los tres siguientes ${ }^{86}$ :

a) La prohibición debe encontrarse recogida en el derecho internacional.

b) Esta prohibición está destinada a proteger valores universales considerados importantes por la totalidad de la comunidad internacional.

c) La infracción de esta prohibición genera una responsabilidad penal individual que debe ser perseguida y castigada por todos los Estados, con independencia de que se encuentre tipificada en los ordenamientos domésticos.

CASSESE, uno de los más respetados expertos en derecho internacional con experiencia profesional en distintas jurisdicciones internacionales, ha defendido largamente que el terrorismo cumple con los requisitos necesarios para ser considerado en el derecho consuetudinario «a discrete international crime perpetrated in time of peace» ${ }^{87}$. Una postura que sin duda complementa la tesis de quienes buscan una juris-

82 Art. 8.2.a) viii), Documentos Oficiales de la Asamblea de los Estados Partes en el Estatuto de Roma de la Corte Penal Internacional, primer período de sesiones, Nueva York, 3 a 10 de septiembre de 2002 (ICCASP/1/3 y Corr. 1), parte II.B, p. 262.

${ }^{83}$ GREVE, cit. supra, p.106.

84 International Criminal Court, The Prosecutor v. Abmad Al Faqi Al Mabdi, ICC-01/12-01/15, 27 de septiembre de 2016.

85 CREEGAN, cit. supra, pp. 251-252.

86 AMBOS, «Creatividad Judicial en el Tribunal Especial para el Líbano...», cit. supra, p. 165; WERLE, cit. supra., p. 32.

${ }^{87}$ CASSESE, «Terrorism is Also Disrupting...», cit. supra., p. 994; CASSESE, A. (2006), «The Multifaceted Criminal Notion of Terrorism in International Law», Journal of International Criminal Justice, Vol. 4, pp. 933-958. 
dicción internacional competente en materia de terrorismo. El TIT contribuiría al viraje hacia la consideración del terrorismo como crimen internacional y, con ello, del derecho penal adjetivo (aspectos complementarios como la cooperación judicial) al derecho penal sustantivo ${ }^{88}$.

No obstante, que el terrorismo sea un crimen internacional autónomo plantea ciertas dudas en la doctrina. En referencia al tercer elemento, la citada decisión del TEL recoge que «it is necessary that States and intergovernmental organisations, through their acts and pronouncements, sanction this attitude by clearly expressing the view that the world community considers the offence at issue as amounting to an international crime» ${ }^{89}$. Este reflejo del requisito de la opinio juris para crear un crimen en el derecho internacional consuetudinario quedaría apoyado por «a number of treaties, UN Resolutions, and the legislative and judicial practice of States ${ }^{90}$. Una afirmación que es verdaderamente arriesgada si se tienen en cuenta los repetidos fracasos por incluirlo en la jurisdicción de la CPI y el largo bloqueo del Convenio General sobre el Terrorismo Internacional $^{91}$. Y son estas mismas razones las que llevan a concluir que «no existe un crimen internacional de terrorismo independiente del derecho penal nacional» ${ }^{92}$.

\section{3. ¿CUÁL SERÍA SU RELACIÓN CON OTROS TRIBUNALES? PRIMACÍA VS COMPLEMENTARIEDAD}

La relación del TIT con otros tribunales nacionales e internacionales podría basarse bien en el principio de primacía (que le permitiría ejercer su jurisdicción incluso cuando el otro tribunal estuviese conociendo del crimen de buena fe) o bien en el de

\footnotetext{
${ }^{88}$ CHERIF BASSIOUNI, «Methodological Options...», cit. supra, pp. 388-396.

89 Véase Interlocutory Decision on the Applicable Law: Terrorism, Conspiracy, Homicide, Perpetration, Cumulative Charging, cit. supra., pár. 91.

${ }^{90}$ Véase ibid., pár. 85. Para un exhaustivo estudio de las decisiones jurisprudenciales nacionales en la lucha contra el terrorismo y el papel de los derechos fundamentales véase GROPPI, T. «El Papel de los Tribunales en el Control de las Medidas contra el Terrorismo Internacional: ¿Hacia un diálogo jurisprudencial?», Revista de Derecho Político, Núm. 86, pp. 309-356. En cuanto a las definiciones en la legislación nacional que violan los derechos fundamentales véase el Informe de la Alta Comisionada de las Naciones Unidas para los Derechos Humanos sobre la protección de los derechos humanos y las libertades fundamentales en la lucha contra el terrorismo, de 2 de junio de 2008, Doc. A/HRC/8/13, párs. 18-23. Disponible en:

https://documents-dds-ny.un.org/doc/UNDOC/GEN/G08/140/36/pdf/G0814036.pdf?OpenElement (Consultado el 21 de julio de 2017).

${ }_{91}$ KIRSCH, S. y OEHMICHEN, A. (2011), «Judges gone astray: The fabrication of terrorism as an international crime by the Special Tribunal for Lebanon», Durbam Law Review, Vol. 32, p. 10. En defensa de la aproximación del TEL véase GILLET, M. Y SCHUSTER, M. (2011), «Fast-track Justice: The Special Tribunal for Lebanon Defines Terrorism», Journal of International Criminal Justice, Vol. 9, p. 1007.

92 AMBOS, «Creatividad Judicial en el Tribunal Especial para el Líbano...», cit. supra, p.166.
} 
complementariedad (en este caso actuaría sólo cuando la jurisdicción competente no pudiera o no quisiera investigar el caso $)^{93}$.

No faltan ejemplos de tribunales internacionales que se rijan por el principio de primacía. La primacía se encuentra en los estatutos de los Tribunales Penales Internacionales para la Antigua Yugoslavia ${ }^{94}$ (en adelante, TPIY) y Ruanda ${ }^{95}$ (en adelante, TPIR), así como en el Tribunal Especial para Sierra Leona (en adelante, TESL) ${ }^{96}$ y el $\mathrm{TEL}^{97}$. Incluso hay quien aboga por incluirlo específicamente en una futura jurisdicción internacional competente en materia de terrorismo: «con detenidos procedentes de una gran variedad de países, normalmente capturados en un segundo país, en ocasiones incluso por fuerzas de un tercer país, el problema de la concurrencia de jurisdicciones y la relación del Tribunal Especial con los tribunales nacionales debe ser clara. Siguiendo los términos de los acuerdos bilaterales, el Tribunal Especial debería tener primacía sobre sobre los tribunales nacionales y nadie podría ser enjuiciado en un tribunal nacional por un acto que ya haya sido sometido al Tribunal Especial» ${ }^{98}$.

El régimen de primacía implica que el tribunal internacional ostenta «una discreción legal sin límites para ordenar a los tribunales nacionales a que le remitan el caso en cualquier momento del procedimiento ${ }^{99}$. Una de las principales razones para optar por la primacía es que la jurisdicción nacional competente esté diseñada para «escudar» a los presuntos criminales. En este sentido se expresaba el TPIY en el caso Tadic: «when an international tribunal such as the present one is created, it must be

${ }_{93}$ DE LA RASILLA, I. (2017), «An International Terrorism Court in nuce in the Age of International Adjudication», Asian Yearbook of Human Rights and Humanitarian Law, Vol. 1, pp. 76-108.

94 Art. 9 del Estatuto del TPIY, cuyo texto con las enmiendas realizadas está disponible en:

http://www.icty.org/x/file/Legal\%20Library/Statute/statute_sept09_en.pdf (Consultado el 21 de julio de 2017).

95 Consejo de Seguridad de Naciones Unidas, Resolución 955 de 8 de noviembre de 1994, Estatuto del Tribunal Internacional para Rwanda, Doc. S/RES/955, art. 8. Disponible en:

http://www.un.org/es/comun/docs/?symbol=S/RES/955\%20(1994) (Consultado el 21 de julio de 2017).

96 Agreement between the United Nations and the Government of Sierra Leone on the establishment of a Special Court for Sierra Leone (with Statute), de 12 de abril de 2002, Recueil des Traités, Vol. 2178, p. 147, art. 8.

${ }_{97}$ Acuerdo entre las Naciones Unidas y la República Libanesa Relativo al establecimiento de un Tribunal Especial para el Líbano, Apéndice, Estatuto del Tribunal Especial para el Líbano, recogido por el Consejo de Seguridad en la Resolución 1717 de 30 de mayo de 2007. Doc. S/RES/1757, art. 4. Disponible en https://documents-dds-ny.un.org/doc/UNDOC/GEN/N07/363/60/pdf/N0736360. pdf?OpenElement (Consultado el 21 de julio de 2017).

${ }_{98}$ GUDE, K. (2006), «After Guantanamo: A Special Tribunal for International Terrorist Suspects», Centre for American Progress, p. 9. Disponible en:

https://cdn.americanprogress.org/wpcontent/uploads/kf/AFTER\%20GUANTANAMO $\% 20$ REPORT.PDF

(Consultado el 21 de julio de 2017)

99 NEWTON, M.A. (2001), «Comparative Complementarity: Domestic Jurisdiction Consistent with the Rome Statute of the International Criminal Court», Military Law Review, Vol. 167, pp. 20-73, p. 42. 
endowed with primacy over national courts. Otherwise, human nature being what it is, there would be a perennial danger of international crimes being characterised as «ordinary crimes», or proceedings being «designed to shield the accused», or cases not being diligently prosecuted ${ }^{100}$. En el caso del TPIR, la razón no era tanto que el sistema protegiese a los sospechosos, sino que los tribunales nacionales careciesen de «los recursos materiales básicos para conducir una investigación efectiva» ${ }^{101}$.

Por otro lado, la complementariedad fue la opción elegida para la non nata CPI de 1937. Aunque estaba ideada para encargarse exclusivamente de crímenes de terrorismo internacional, esto no excluía que otras jurisdicciones fuesen competentes para conocer estos delitos. Según el art. 2 de su Convención, los Estados parte ostentaban la «faculté de déferer» a la CPI a los acusados de haber cometido los actos contenidos en la CIPRT. Como alternativa al enjuiciamiento interno y la extradición, su jurisdicción no era exclusiva ni obligatoria sino subsidiaria o complementaria ${ }^{102}$.

Este principio quedó reflejado en la competencia ratione personae. El art. 2 contemplaba que el Estado requerido sólo podía referir a la CPI aquellos casos en los que, según su ordenamiento interno, fuese competente para juzgar al acusado o pudiera autorizar la solicitud de extradición. El sometimiento del acusado a este tribunal internacional no podía suponer más que una «délegation de compétence» ${ }^{103}$. Si el Estado requerido no podía juzgar ni extraditar conforme a sus normas internas, no existía competencia ni poder alguno que delegar a la CPI para que se encargase de conocer del asunto. Y para el supuesto de que un acusado fuese referido a la CPI, el art. 21 contemplaba que la ley sustantiva aplicable sería la menos severa a escoger entre la del Estado donde se hubiera cometido la infracción y la del Estado que hubiese remitido el caso a la $\mathrm{CPI}^{104}$.

100 Tribunal Penal Internacional para la Antigua Yugoslavia, Prosecutor v. Dusko Tadic, Decision on the Defence Motion for Interlocutory Appeal on Jurisdiction, 2 de octubre de 1995, Case No IT-94-1-AR72, pár. 58 .

101 HELLER, K.J. (2012), «A Sentence-Based Theory of Complementarity», Harvard International Law Journal, Vol. 53, Núm.1, pp. 202-249, p. 208.

102 SOTTILE, cit. supra., p. 143.

103 Véase ibid., p. 149. El profesor Pella explicaba la naturaleza de esta jurisdicción en los siguientes términos: "This system does not in any way curtail a State's right to try persons who have committed acts of terrorism in its territory or persons guilty of such acts who have taken refuge therein. Exercise of jurisdiction by an international court would therefore only be conceivable if the State which held the accused in custody voluntarily renounced its right to exact punishment. It might even be said that this conception resembles to a certain extent the idea of jurisdiction by delegation». La intervención está recogida en FERENCZ, B. (1980), An International Criminal Court: A Step Towards World Peace - A Documentary History and Analysis: Volume I, A Half Century of Hope, London, Oceana Publications, p. 289.

104 El art. 21 se pronuncia así:

«1. En ce qui concerne l'application de la loi pénale de fond, la Cour appliquera la loi la moins rigoureuse. A cet effet, elle prendra en consideration la loi du pays sur le teritoire duquel l'infraction a été commise et la loi du pays qui a saisi la Cour.

2. Pour toutes contestations sur la question de savoir quelle est la loi pénale de fond à appliquer, la Cour statuera». 
Dado el sometimiento a la ley nacional sustantiva de los Estados implicados, esta CPI llegó a considerarse como un experimento a clasificar, más que como el comienzo de un derecho penal internacional sustantivo, como una suerte de avance del proceso penal internacional ${ }^{105}$. La complementariedad llevó a DE VABRES a concluir que «la grave innovation que constitue la création d'un tribunal répressif international est introduite avec timidité, et comme par la porte de service» ${ }^{106}$.

La complementariedad ha sido también la opción elegida para la actual $\mathrm{CPI}^{107}$. Su jurisdicción queda firmemente sujeta a este principio según el cual «tendrá carácter complementario de las jurisdicciones penales nacionales» ${ }^{108}$ e inadmitirá cualquier asunto cuando «sea objeto de una investigación o enjuiciamiento por un Estado que tenga jurisdicción sobre él, salvo que éste no esté dispuesto a llevar a cabo la investigación o el enjuiciamiento o no pueda realmente hacerlo» ${ }^{109}$.

¿Cuáles son las ventajas de un régimen basado en la complementariedad? Tres son las principales identificadas ${ }^{110}$. La primera de ellas es el respeto a la soberanía de los Estados en relación con el ejercicio del ius puniendi. Este «horizontal non-hierarchical order» facilita que un mayor número de Estados se adhiera a una jurisdicción internacional de esta magnitud ${ }^{111}$. En segundo lugar, una estrecha relación entre la jurisdicción internacional y las jurisdicciones nacionales contribuye a evitar la impunidad de quienes cometen los crímenes más graves contra la comunidad internacional $^{112}$. Por último, se encuentra el interés práctico de reservar los limitados recursos de una jurisdicción internacional para los casos más graves confiando en que las jurisdicciones nacionales puedan hacerse cargo del resto de casos con más eficacia dada su cercanía a las pruebas y el mejor conocimiento del contexto en que se cometieron

105 STARKE, J.G., «The Convention for the Creation of an International Criminal Court», British Yearbook of International Law, vol. 19, 1938, pp. 216-217, p. 217.

106 DONNEDIEU DE VABRES, H. (1938), «La répression internationale du terrorisme: Les conventions de Gèneve (16 novembre 1937)», Revue de Droit International et de Législation comparée, Vol. 19, pp. 37-74, p. 61.

107 En los últimos años la CPI ha realizado una amplia labor de divulgación del principio de complementariedad que ha dado como resultado un completo manual al respecto. Véase SEILS, P. Handbook on Complementarity: An Introduction to the Role of National Courts and the ICC in Prosecuting International Crimes. Disponible online en:

https://www.ictj.org/sites/default/files/ICTJ_Handbook_ICC_Complementarity_2016.pdf (Consultado el)

108 Art. 1 del Estatuto de Roma.

109 Art. 17.1.a) del Estatuto de Roma.

110 TRAHAN, J. (2012), «Is Complementarity the Right Approach for the International Criminal Court's Crime of Aggression? Considering the Problem of Overzealeous National Court Prosecutions», Cornell International Law Journal, Vol. 45, p. 578.

111 FALK, R.A. (1959), «International Jurisdiction: Horizontal and Vertical Conceptions of Legal Order», Temple Law Quaterly, Vol. 32, pp. 295-320; BOISTER, N. (2012), «International Tribunals for Transnational Crimes: Towards a Transnational Criminal Court? Criminal Law Forum, Vol. 23, pp. $295-$ 318, p. 313.

112 TRAHAN, cit. supra., p. 579. 
los crímenes ${ }^{113}$. Una regla que, en definitiva, no es sólo «una concesión reluctante a la realpolitik sino también una regla substantiva y operativa que reconoce que la cercanía al escenario de los eventos en cuestión supone un inherente valor tanto práctico como expresivo» ${ }^{114}$.

Parece que el nuevo TIT apostaría por el principio de complementariedad en su relación tanto con los tribunales nacionales como con la CPI: «primero, debería ser complementario de los tribunales nacionales y actuar sólo en aquellos casos en los que el estado competente no quiere o no puede actuar en la sanción del acto de terrorismo perpetrado. De esta forma el tribunal actuaría de la mejor manera con vistas a fortalecer la capacidad nacional en la lucha contra el terrorismo; segundo, debería ser complementario a la jurisdicción de la Corte Penal Internacional en aquellos casos en los que los actos de terrorismo puedan dar lugar a crímenes establecidos bajo la jurisdicción de la $\mathrm{CPI} \gg^{115}$. A fin de cuentas, no puede descartarse que la jurisdicción de la CPI opere de manera indirecta sobre actos cometidos por terroristas que cumplan los requisitos de los crímenes recogidos en el Estatuto. Pese a las virtudes de la complementariedad, esta relación con la CPI ya ha hecho surgir algunas dudas que deberán tenerse en cuenta durante el desarrollo del proyecto: ¿podría intervenir el TIT en aquellos casos en que la CPI tiene jurisdicción, pero no la ejerce? ¿Habría en este caso posibilidad de forum shopping por parte de los Estados y el Consejo de Seguridad entre ambos tribunales? ${ }^{116}$

\section{4. ¿CÓMO FUNDARLO? LEGITIMIDAD Y CONSENSO VS RAPIDEZ Y EFICACIA}

Una vez esbozado el contenido del TIT, faltaría determinar el instrumento más apto para su creación. La opción ideal, tal y como destacan los promotores del TIT, sería un tratado internacional que implicase «una base legal fuerte y coherente, con apoyo y compromiso internacional en todo el mundo» ${ }^{117}$. En efecto, esta fue la base elegida tanto para la fallida CPI de 1937 como para la actual CPI al suponer que era «probablemente la más acorde con el principio clásico de la soberanía estatal, que recoge la norma según la cual es prerrogativa del estado decidir a qué normas de derecho internacional o a qué tratados quedará sujeto según el consentimiento que

113 BENZING, M. (2003), «The Complementarity Regime of the International Criminal Court: International Criminal Justice between State Sovereignty and the Fight against Impunity», Max Planck Yearbook of United Nations Law, Vol. 7, pp. 591-632, pp. 599-560.

114 ALVAREZ, J.E. (2003), «The New Dispute Settlers: (Half) Truths and Consequences», Texas International Law Journal, Vol. 38, pp. 405-444, p. 437.

115 AURESCU, «Establishing an International Court...», p. 115.

116 PANTALEO, L. y RIBBELINK, O. (2016), «The Establishment of a Special Court against Terrorism», EJIL:Talk! Disponible en: https:/www.ejiltalk.org/the-establishment-of-a-special-courtagainst-terrorism/ (Consultado el 21 de julio de 2017)

117 AURESCU, «Establishing an International Court...», p. 114. 
para ello exprese» ${ }^{118}$. Y sería, además, la más coherente con una propuesta que busca reforzar «los esfuerzos de la comunidad internacional en la lucha contra el terrorismo y añadiría credibilidad y legitimidad a esta maniobra por la neutralidad e independencia de este tribunal internacional» ${ }^{119}$.

No obstante, hay que reconocer que optar un tratado internacional comporta ciertas desventajas frente a una amenaza en constante crecimiento como es el terrorismo. La principal es, tal y como se ha experimentado en el marco de otros tribunales internacionales, la gran dilatación temporal que se produce tanto en las propias negociaciones para adoptar un estatuto como en el posterior proceso de ratificaciones $^{120}$.

La alternativa se encuentra en la aprobación por el Consejo de Seguridad de Naciones Unidas (en adelante, CSNU) de una resolución en el marco del Capítulo VII de la Carta. Conforme a los arts. 39 y 41 de dicho texto, el CSNU puede adoptar medidas que no impliquen el uso de la fuerza para restablecer la paz y seguridad internacionales en los casos en que ya haya determinado una amenaza o quebrantamiento de ésta. En el caso del terrorismo, cumplir con el requisito de ser una amenaza a la paz y seguridad internacional no es ningún obstáculo. Desde los fatídicos atentados del 11 de septiembre de 2001, el CSNU viene afirmando que «todo acto de terrorismo internacional constituye una amenaza para la paz y la seguridad internacionales» ${ }^{121}$.

La creación de un tribunal internacional por la vía del CSNU no sería desde luego una novedad. Tanto el TPIY como el TPIR fueron creados por sendas resoluciones en el marco del Capítulo VII de la Carta ${ }^{122}$. La diferencia sin precedentes, tal y como

118 VAN GINKEL, cit. supra., pp. 153-154.

119 AURESCU, «Establishing an International Court...», p. 114.

120 VAN GINKEL, cit. supra., p. 153; AURESCU, «Establishing an International Court...», cit. supra., p. 114

${ }_{121}$ Consejo de Seguridad de Naciones Unidas, Resolución 1373 de 28 de septiembre de 2001, Doc. S/RES/1373, p. 1. Disponible en:

https:/documents-dds-ny.un.org/doc/UNDOC/GEN/N01/557/46/pdf/N0155746.pdf?OpenElement (Consultado el 21 de julio de 2017).

Para un estudio de las distintas fases del CSNU en cuanto a la consideración del terrorismo como amenaza a la paz y la seguridad internacionales véase SANTORI, V. (2006). «The UN Security Council's (Broad) Interpretation of the Notion of the Threat to Peace in Counter-Terrorism», en NESI, G. (ed.), International Cooperation in Counter-Terrorism: The United Nations and Regional Organizations in the Fight Against Terrorism, Hampshire, Ashgate Publishing, pp. 89-119.

122 Resolución 808 del Consejo de Seguridad de Naciones Unidas, S/RES/808, de 22 de febrero de 1993, disponible en:

https://documents-dds-ny.un.org/doc/RESOLUTION/GEN/NR0/702/72/img/NR070272. pdf? OpenElementy (Consultado el 21 de julio de 2017)

Resolución 955 del Consejo de Seguridad de Naciones Unidas, S/RES/955, de 8 de noviembre de 1994. Disponible en:

https://documents-dds-ny.un.org/doc/UNDOC/GEN/N94/437/51/pdf/N9443751.pdf?OpenElement (Consultado el 21 de julio de 2017). 
resaltan los promotores del TIT, es que no conocería de amenazas bien definidas en el tiempo y el espacio sino sobre la amenaza general del terrorismo internacional ${ }^{123}$. Al contrario que en el caso de los tribunales anteriores, que tienen una competencia temporal y geográfica definida a extinguir una vez finalizada su tarea, que este nuevo tribunal «pueda estar dedicado a perseguir actos de terrorismo es una adivinanza práctica en tanto que el terrorismo es un fenómeno perenne cuyas motivaciones han sido tan variadas como distintos sus objetivos» ${ }^{124}$.

La rapidez que teóricamente ofrece una resolución del CSNU frente a un tratado internacional ha hecho que los defensores del TIT se decanten por esta opción ${ }^{125}$. En efecto, «con esta opción se evitaría el lento proceso de negociaciones por los estados interesados. Después de todo, con esta opción solo 9 de los 15 miembros del Consejo de Seguridad tendrán que emitir un voto concurrente para adoptar la resolución» ${ }^{126}$. A ello se suma el atractivo de una mayor eficacia ya que el TIT «tendría los poderes perentorios del Consejo de Seguridad y no tendría que confiar necesariamente en complicados tratados de extradición y cooperación para obtener pruebas y sospechosos. Un solo juego de normas procesales y sustantivas se aplicaría a todas las partes en tanto que el tribunal siguiese en funcionamiento, y esta unidad eliminaría la inseguridad y pronunciamientos en ocasiones injustos que surgen de procedimientos individuales en foros menos integrados» ${ }^{127}$.

Pero estas virtudes deben ser atemperadas tras un análisis más profundo. Si bien en el proceso de aprobación de una resolución del CSNU el número de partes negociadoras es mucho menor que en un tratado internacional, no debe olvidarse que el poder de veto de los miembros permanentes puede hacer peligrar su nacimiento ${ }^{128}$. Por otro lado, la reparación del déficit de legitimidad en la lucha contra el terrorismo que pretende esta propuesta podría verse debilitada por esta vía ${ }^{129}$. Tal es así «si lo que se pretende es el respaldo de un gran consenso de la comunidad internacional, dado el carácter eminentemente restringido del órgano que lo crearía y de la necesidad de que este ejerciera de nuevo una competencia cuasi legislativa, con las críticas que ello ha puesto ya en relación a otras actuaciones de tipo normativo del CSNU» ${ }^{130}$. Una solución intermedia podría consistir, como destaca algún autor y parecen plantearse los promotores del TIT, en recurrir inicialmente a una resolución del CSNU que diese una competencia temporal al tribunal a la espera de la constitución de un tratado internacional al respecto ${ }^{131}$.

\footnotetext{
${ }^{123}$ AURESCU, «Establishing an International Court...», cit. supra, p. 115.

124 GOLDSTONE, cit. supra., p. 20.

125 AURESCU, «Establishing an International Court...», cit. supra, p. 115.

126 VAN GINKEL, cit. supra., 156.

127 GOLDSTONE, p. 20.

128 VAN GINKEL, cit. supra, p. 156; GOLDSTONE, cit. supra., p. 20.

129 PANTALEO, cit. supra.

130 SALINAS DE FRÍAS, «Lucha contra el terrorismo internacional...», cit. supra., p. 246

131 DE LA RASILLA, cit. supra.
} 


\section{5. ¿HACIA UNA SUPERACIÓN DE LOS OBSTÁCULOS JURÍDICOS A NIVEL POLÍTICO?}

Las trabas jurídicas incluyen la falta de claridad en los elementos de la definición del crimen de terrorismo y la inexistencia de opinio iuris en cuanto a su naturaleza de crimen internacional. Ahora bien, ¿a qué se debe la ausencia de acuerdo político que tiene este reflejo en el terreno normativo? Todo podría ser superado si se avanzase en el Convenio General sobre el Terrorismo Internacional y existiesen declaraciones suficientes para considerar el terrorismo como crimen internacional en el derecho consuetudinario. De igual modo, este cambio podría alcanzarse en el marco de las negociaciones que diesen fruto al TIT. En efecto, «el derecho no permanece siendo el mismo, inamovible, invariable y rígido hasta el fin de los tiempos» ${ }^{132}$. Incluso los autores críticos con el pronunciamiento del TEL reconocen que el terrorismo se encuentra «entre un delito transnacional ordinario basado en un tratado y un crimen internacional en sentido estricto. Se puede decir que está en camino hacia el nivel supremo de un auténtico crimen internacional» ${ }^{133}$.

Entonces, ¿qué hay en el camino que impide avanzar a los actores políticos relevantes hacia esa definición del terrorismo y su consideración como crimen internacional? La respuesta parece encontrarse en la aplicación del crimen de terrorismo al ejercicio del derecho a la libre determinación de los pueblos y a los agentes del Estado que actúan en contra del ordenamiento jurídico internacional en el marco de un conflicto armado (el denominado terrorismo de Estado) ${ }^{134}$.

El último informe del comité especial encargado del proyecto de Convenio General sobre el Terrorismo Internacional recoge claramente los desacuerdos al respecto: «varias delegaciones destacaron la necesidad de que el proyecto de convenio incluyera una definición clara de terrorismo que distinguiera entre los actos de terrorismo y la lucha legítima de los pueblos bajo ocupación extranjera y dominación colonial o externa en el ejercicio de su derecho a la libre determinación, reconocida en la resolución 46/51 de la Asamblea General y en otros documentos conexos de las Naciones Unidas. Algunas delegaciones opinaron que, para que fuera general, el proyecto de convenio debía incluir el concepto de terrorismo de Estado, incluidos los actos cometidos por las fuerzas militares de un Estado. A ese respecto, se señaló que la definición de terrorismo que figuraba en el proyecto de art. 2 debería incluir las actividades de las personas que estuvieran al mando de las fuerzas armadas de un Estado, o que controlaran

132 VENTURA, M.J. (2011), «Terrorism According to the STL's Interlocutory Decision on the Applicable Law; A Defining Moment or a Moment Defining?», Journal of International Criminal Justice, Vol. 9, Núm. 5, p. 1041.

133 AMBOS, «Creatividad Judicial en el Tribunal Especial para el Líbano... », cit. supra, pp. 166-167.

134 VACAS FERNÁNDEZ, F. (2011), El terrorismo como crimen internacional, Valencia, Tirant Lo Blanch, p. 168; PERÉZ GONZÁLEZ, M. y CONDE PÉREZ, E. (2012), Lucha contra el Terrorismo, Derecho Internacional Humanitario y Derecho Penal Internacional, Valencia, Tirant Lo Blanch, p. 31. 
grupos armados, en los casos en que esas actividades no se rigieran por el derecho internacional humanitario» ${ }^{135}$.

La controversia sobre la inclusión de los movimientos de liberación nacional se remonta a principios de los años setenta. Los fatídicos atentados perpetrados durante las Olimpiadas de Múnich de 1972, sumados al ataque en el Aeropuerto de Lod y al tiroteo contra el embajador soviético ante Naciones Unidas en Nueva York, volvieron a poner sobre la mesa de la Asamblea General el problema del terrorismo internacional ${ }^{136}$. Durante el vigésimo séptimo periodo de sesiones, el Secretario General Waldheim solicitó incluir un tema relativo a las medidas para prevenir el terrorismo internacional ${ }^{137}$, siendo Estados Unidos el primero en responder al llamamiento del Secretario General con un proyecto de Convención para la Prevención y Sanción de Ciertos Actos de Terrorismo Internacional ${ }^{138}$. La propuesta estadounidense, sin embargo, se enfrentaba a una Asamblea General bloqueada por las políticas de la Guerra Fría y uno de los grandes desafíos de su historia: el derecho a la libre determinación de los pueblos coloniales ${ }^{139}$.

Doce años atrás, la Asamblea General había aprobado la Resolución 1514 (XV) cuyo título rezaba «Declaración sobre la concesión de la independencia a los países y pueblos coloniales» ${ }^{140}$. Se iniciaba así el camino de la legitimación de las denominadas «guerras de liberación nacional» ${ }^{141}$. No fueron pocos los países que consiguieron la independencia gracias a este ejercicio de violencia política, y que aún la apoyaban

135 Asamblea General de Naciones Unidas, Informe del Comité Especial establecido en virtud de la resolución 51/210 de la Asamblea General, de 17 de diciembre de 1996, 16. ${ }^{\circ}$ período de sesiones, del 8 al 12 de abril de 2013, Doc. A/68/37, p. 23. Las cursivas del texto están añadidas. Disponible en https:// documents-dds-ny.un.org/doc/UNDOC/GEN/N13/292/55/pdf/N1329255.pdf?OpenElement (Consultado el 21 de julio de 2017). La reticencia a incluir los actos cometidos por las fuerzas armadas en períodos de conflicto armado queda claramente reflejada en la reciente Directiva del Parlamento Europeo y del Consejo relativa a la lucha contra el terrorismo, cit. supra, considerando 37.

136 MURPHY, J. (1975), «United Nations Proposal on the Control and Repression of Terrorism», en CHERIF BASSIOUNI, M. (ed.), International Terrorism and Political Crimes, Springfield, Charles C. Thomas, pp. 493-506, p. 496.

137 Nota del Secretario General de 8 de septiembre de 1972, Doc. A/8791, Anexos XXVII, p. 92. Disponible en:

https:/documents-dds-ny.un.org/doc/UNDOC/GEN/N72/173/21/pdf/N7217321.pdf?OpenElement (Consultado el 21 de julio de 2017).

${ }^{138}$ US Draft Convention for the Prevention and Punishment of Certain Acts of International Terrorism, reproducida en UN Document A/C.6/L.850, de 25 de septiembre de 1972 y publicada en International Legal Materials, 1972, vol. II, pp. 1382-1387.

139 SAUL, «Attemps to Define Terrorism...», cit. supra, p. 70.

140 Asamblea General de Naciones Unidas, Resolución 1514 (XV) de 14 de diciembre de 1960. Disponible online en:

https://documents-dds-ny.un.org/doc/RESOLUTION/GEN/NR0/156/42/img/NR015642. pdf? OpenElement (Consultado el 21 de julio de 2017).

${ }^{141}$ CLAUDE, I.L., «Collective Legitimization as a Political Function of the United Nations», International Organizations, Vol. 20, Núm .3, 1966, pp. 367-379. 
en lugares como Palestina y Sudáfrica ${ }^{142}$. Para este grupo de países de reciente incorporación a las Naciones Unidas, la propuesta estadounidense se veía como una condena de las guerras de liberación nacional bajo la etiqueta de «terrorismo». El denominado grupo de países no alineados, con Argelia como «punta de lanza» ${ }^{143}$, defendía en cambio que la verdadera amenaza era el «terrorismo de estado» reflejado, por ejemplo, en los actos de gobiernos que luchaban en contra del derecho a la libre determinación ${ }^{144}$.

La férrea defensa de los movimientos de liberación nacionalpor parte de los países no alineados ha dado lugar a críticas dado que la legitimación de estos movimientos no autoriza cometer cualquier tipo de acto. Tal y como recuerda MOORE, el art. 3 común a los cuatro Convenios de Ginebra prohíbe, en el marco de los conflictos armados no internacionales, los «atentados contra la vida y la integridad corporal»y la «toma de rehenes» cuando las víctimas no participen en las hostilidades ${ }^{145}$. En cuanto a la cuestión del terrorismo de Estado, es común defender que dichos actos ya caen en el ámbito de aplicación de una rama distinta del ordenamiento internacional: el derecho internacional humanitario ${ }^{146}$. Los actos de terrorismo en el marco de los conflictos armados internacionales están prohibidos por el art. 33 de la Cuarta Convención de Ginebra y el art. 51.2 de su Protocolo Adicional I, así como en los conflictos armados no internacionales por el mencionado art . 3 común y los arts. 4.2.d) y 13.2 del Protocolo Adicional II. Unas prohibiciones que, conforme a la sentencia del TPIY en el caso Galic, se encuentran no sólo en el texto de los tratados sino que forman ya también parte del derecho consuetudinario ${ }^{147}$.

La controversia política que rodea a la distinción entre los grupos liberación nacional y los grupos terroristas se resume con la conocida frase «one man's freedom fighter is another man's terrorist ${ }^{148}$. Pese a los intereses contrapuestosy variables

${ }_{142}$ BLUMENAU, B., «The United Nations and West Germany's efforts against international terrorism in the 1970s», en HANHIMÄKI, J.M. y BLUMENAU B. (eds.), An International History of Terrorism: Western and non-Wextern experiences, Routledge, Oxon, 2013, p. 71.

${ }^{143}$ FRIEDRICHS, J., «Defining the International Public Enemy: The Political Struggle behind the Legal Debate on International Terrorism», Leiden Journal of International Law, Vol. 19, 2006, pp. 69-91, p. 72.

${ }^{144}$ Para un estudio del régimen aplicable a los movimientos de liberación nacional en un caso concreto, como fue el de Namibia bajo ocupación sudafricana, véase GAUTHIER, S., «SWAPO, the United Nations, and the struggle for national liberation», en HANHIMÄKI, cit. supra, pp. 169-188.

145 MOORE, J.N., «Towards Legal Restraints on International Terrorism», The American Journal of International Law, Vol. 67, Núm. 5, 1973, pp. 87-94, p. 88.

${ }_{146}$ Para un estudio detallado véase PEJIC, J. (2012), «Armed Conflict and Terrorism: There is a (Big) Difference», en SALINAS DE FRÍAS, A.M., SAMUEL, K.L.H. y WHITE, N.D., Counter-terrorism: International Law and Practice, Oxford, Oxford University Press, pp. 171-204.

147 Tribunal Penal Internacional para la Antigua Yugoslavia, Prosecutor v Stanislav Galic (Appeal Chamber Judgment), 30 de noviembre de 1996, Case No IT-08-29-A, pár. 87.

148 PEJIC, J. (2012), «Armed Conflict and Terrorism: There is a (Big) Difference», en SALINAS DE FRÍAS, A.M., SAMUEL, K.L.H. y WHITE, N.D., Counter-terrorism: International Law and Practice, Oxford, Oxford University Press, p. 196. 
de cada Estado que convergen en este ámbito ${ }^{149}$, no puede ignorarse la existencia de ciertos avances hacia un consenso común. Si bien aún hay Estados contrarios al respecto, los Estados de la Organización para la Cooperación Islámica ya han comenzado a aceptar la exclusión del terrorismo de Estado a cambio de que la violencia política ejercida por los movimientos de liberación nacional queden aparte también ${ }^{150}$.

Una forma de evitar esta controversia política consiste en restringir, como pretende hacer la propuesta que aquí se comenta, la jurisdicción del TIT a los actos cometidos en tiempo de paz. No obstante, ya hay quien destaca que esta delimitación puede ser problemática en aquellos casos en los que la existencia y naturaleza de un conflicto armado no está clara, como en los conocidos por el TJUE en referencia a Hamás o a los Tigres para la Liberación del Eelam Tamil ${ }^{151}$.

149 Un ejemplo ilustrativo es el de los talibanes que «were once called freedom fighters (mujahideen) and backed by the CIA when they were resisting the Soviet occupation in Afghanistan», y que luego pasaron a formar parte del «top of the international terrorist lists». Véase ZEIDAN, S. (2004), «Desperately Seeking Definition: The International Community's Quest for Identifying the Specter of Terrorism», Cornell International Law Journal, Vol. 36, Núm. 3, pp. 491496, p. 492.

150 El último texto propuesto por los Estados miembros de la Organización para la Conferencia Islámica excluye los actos cometidos en los dos contextos. Asamblea General de Naciones Unidas, Informe del Comité Especial establecido en virtud de la resolución 51/210 de la Asamblea General, cit. supra, p. 19. Los términos empleados son los siguientes:

«2. Las actividades de las partes durante un conflicto armado, incluso en situaciones de ocupación extranjera, según se entienden esos términos en el derecho internacional humanitario, y que se rijan por ese derecho, no estarán sujetas al presente Convenio.

3. Las actividades realizadas por las fuerzas militares de un Estado en el cumplimiento de sus funciones oficiales, en la medida en que se ajusten al derecho internacional, no estarán sujetas al presente Convenio».

151 PANTALEO, cit. supra.

La reciente sentencia sobre los Tigres para la Liberación del Eelam Tamil no se pronuncia sobre la naturaleza del conflicto. Para determinar si pueden imponerse o no sanciones por los actos cometidos en el marco de conflictos armados, en el sentido del Derecho Internacional Humanitario, el TJUE distingue entre las medidas de derecho punitivo adoptadas en el marco de la justicia y asuntos de interior (que excluye expresamente los actos cometidos en los conflictos armados) y las medidas de prevención y obstaculización adoptadas en el ámbito de la política exterior y de seguridad común (y de la que no se excluyen expresamente los actos cometidos en este contexto). Si se asimila el futuro TIT a una suerte de herramienta de derecho punitivo, no podría conocer del caso de los Tigres por su encuadramiento en un conflicto armado, y ello pese a que TJUE sí entre a conocer en cuanto a la imposición de sanciones PESC. Véase la Sentencia del TJUE en A y otros contra Minister van Buitenlandse Zaken, C-158/14, ECLI:EU:C:2017:202. Para una revisión más reciente del TJUE de las sanciones contra estos dos grupos véanse la Sentencia del TJUE en Consejo de la Unión Europea contra Liberation Tigers of Tamil Eelam, C-599/14, ECLI:EU:C:2017:583; y la Sentencia del TJUE en Consejo de la Unión Europea contra Hamás, C-79/15, ECLI:EU:C:2017:584. 


\section{CONCLUSIONES}

Las dos preguntas iniciales de este estudio pretendían poner sobre la mesa los principales desafíos a los que se va a enfrentar el TIT y determinar si tal jurisdicción supondría la herramienta legal perfecta en la lucha contra el terrorismo internacional. La propuesta contiene por su naturaleza un mérito indiscutible: el recurso a los medios legales para combatir un fenómeno que, por desgracia, está ocasionando un fuerte déficit de legitimidad en la acción internacional por la extensión del uso de la fuerza armada y la disminución del peso de la libertad en su sempiterna búsqueda de equilibrio con la seguridad.

La tormenta jurídica y política a la que se enfrenta esta propuesta hace difícil que pueda llegar a buen puerto. La nave, aún en los astilleros, está siendo diseñada con unos objetivos claros: que sea un instrumento eficaz, que esté respaldado por un amplio consenso de la comunidad internacional y que sea creado de la forma más rápida posible. Sin embargo, una vez examinados los elementos que la componen, surgen dudas en torno a la presencia equilibrada de todos estos objetivos en su diseño.

El problema de la indefinición del terrorismo intenta solucionarse, en cuanto al elemento objetivo, por referencia a los convenios internacionales ya existentes sobre lucha contra el terrorismo. Esta fórmula permitiría obtener un mayor consenso entre los miembros de la comunidad internacional. Pero la eficacia del TIT se ve reducida ya que deja fuera gran parte de los métodos empleados actualmente en los atentados terroristas. Respecto al elemento subjetivo, el resultado es el opuesto. La inclusión de motivos políticos o ideológicos puede restar apoyos, si bien es necesaria para tener una definición eficaz que tenga en cuenta la propia naturaleza del terrorismo. También es polémica la existencia de una opinio juris en el derecho consuetudinario sobre el terrorismo como un crimen internacional que sostenga el desarrollo de un derecho penal sustantivo frente a un crimen transnacional perseguible mediante herramientas adjetivas de cooperación penal.

El consenso y la legitimidad también motivan esa opción por la complementariedad como régimen de relaciones con la CPI y los tribunales nacionales, así como por reducir la jurisdicción a los actos cometidos en tiempo de paz. Sin embargo, no quedan claros algunos aspectos que harían peligrar su eficacia. Por ejemplo, lo que ocurriría en aquellos casos en que la CPI sea competente, pero decida no entrar a conocer, o cuando la propia existencia de un conflicto armado sea confusa. El consenso parece ser el objetivo principal de los defensores de esta propuesta, y se sacrifica la eficacia del TIT cuando se estima necesario. Sin embargo, el recurso a una resolución del CSNU para su creación provocaría el hundimiento de la legitimidad y el consenso de esta compleja nave antes incluso de que salga a flote.

A los nada desdeñables problemas jurídicos y políticos que se abaten en torno a esta propuesta se suma el mal encaje de algunos de sus elementos internos en el resto del diseño. Pero ello no quiere decir que, aunque la propuesta no alcance el éxito, los esfuerzos sean en vano. El propio debate sobre el mayor uso de herramientas de dere- 
cho internacional penal en la lucha contra el terrorismo puede generar avances y desbloquear posturas políticas, sino en el contexto de esta propuesta concreta, en otros foros relevantes. Y, en cualquier caso, como ya defendió Salvador de Madariaga con respecto a la CPI de 1937, «laws and conventions were in themselves educational. The present was a happy moment for giving this idea a trial, and even if it failed, could it really do any harm? ${ }^{152}$.

\section{Title}

The proposal for an International Court against terrorism: legal and political challenges.

\section{Summary:}

1. Introduction. What Acts Could be Judged? Definition and Nature of the Crime of Terrorism: 2.1 The eternal search of the definition of terrorism. 2.2 International crime vs transnational crime. 3. What Would be its Relationship with other Tribunals? Primacy vs Complementarity. 4. What Would be its Legal Basis? Legitimacy and Consensus vs Promptness and Effectiveness. 5. Towards a Political Solution for the Legal Obstacles? 6. Conclusion.

\section{Resumen:}

La propuesta presentada por España y Rumanía para la creación un Tribunal Internacional contra el Terrorismo es una respuesta jurídica clásica a una de las mayores amenazas de la actualidad. Desde principios del siglo $\mathrm{xx}$ numerosos proyectos han tratado de incluir el crimen de terrorismo en una jurisdicción internacional de alcance general, ya sea como competencia exclusiva o como parte de una lista más amplia de crímenes. Diversos obstáculos jurídicos y políticos han evitado cualquier avance en este ámbito. En el presente artículo se analizan cuáles son los principales elementos de la nueva propuesta y los problemas que plantean, para así determinar la viabilidad que tiene para pasar de una situación de lege feren$d a$ a lege data. El debate principal gira en torno a la definición del crimen de terrorismo; su naturaleza; la relación de este nuevo tribunal con los ya existentes; la herramienta para su fundación y el conocido impasse político sobre el terrorismo de Estado y los movimientos de liberación nacional. El

152 League of Nations Council Resolution of 10 December 1934, Proceedings of the International Conference on the Repression of Terrorism, Geneva, 1 June 1938, Annex 1, p.68. 
estudio de estos elementos muestra el objetivo de obtener el mayor consenso posible en torno a esta propuesta en detrimento de la eficacia, si bien ciertos aspectos propios y foráneos acaban erosionando esta meta y hacen surgir serias dudas sobre el éxito del proyecto. Independientemente del resultado final, el proyecto merece una especial consideración por ofrecer una respuesta basada en el imperio de la ley en la lucha contra una amenaza que está provocando la disipación de ciertos principios básicos para la convivencia pacífica de la comunidad internacional.

\begin{abstract}
:
The proposal put forward by Spain and Romania for the creation of an International Court Against Terrorism is a traditional legal response to one of the most serious threats of our time. From the beginning of the $20^{\text {th }}$ century, several projects have considered the possibility of including the crime of terrorism in an international jurisdiction with general scope, either as an exclusive competence or as a part of a wider list of crimes. However, certain legal and political obstacles have blocked the developments in this field. This article analyses the main elements and problems of this new proposal in order to determine its viability to evolve from lege ferenda to lege data.

The debate revolves around the definition and nature of the crime of terrorism, as well as the relationship with other tribunals, the legal foundation and the well-known political impasse about state terrorism and national liberation movements. The study of these elements shows the aim to reach a consensus at the expense of effectiveness. Nevertheless, this goal is hindered by certain aspects, both internal and external to this proposal, raising serious doubts over the success of this project. Regardless of the outcome, this initiative is a response based on the rule of law against a threat that is disrupting certain basic principles for the pacific coexistence of the international community and, as such, it deserves thorough consideration.
\end{abstract}

\title{
Palabras clave:
}

Terrorismo, derecho internacional penal, legitimidad, eficacia, intereses políticos

\section{Key words:}

Terrorism, international criminal law, legitimacy, effectiveness, political interests 